\title{
AGENDAS EN COMPETENCIA PARA ABORDAR LA VIOLENCIA INTRAFAMILIAR: JUSTICIA RESTAURATIVA VS. PUNITIVISMO*
}

\author{
COMPETING AGENDAS TO ADDRESS \\ DOMESTIC VIOLENCE: RESTORATIVE \\ JUSTICE V. PUNITIVE APPROACHES
}

Astrid Liliana Sánchez-Mejía**

Fecha de recepción: 9 de marzo de 2016 Fecha de aceptación: 3 de mayo de 2016 Disponible en linea: 31 de mayo de 2016

\section{Para citar este artículo/To cite this article}

Sánchez-Mejía, Astrid Liliana, Agendas en competencia para abordar la violencia intrafamiliar: justicia restaurativa vs. punitivismo, 132 Vniversitas, 423-482 (2016). http://dx.doi.org/10.11144/Javeriana.vj132.acav

doi:10.11144/Javeriana.vj132.acav

* Este trabajo es resultado de investigación en el marco de la línea de justicia del Grupo de Investigación en Justicia Social de la Facultad de Ciencias Jurídicas, Pontificia Universidad Javeriana. Quiero expresar mi gratitud a Máximo Langer por sus comentarios detallados y profundos a versiones anteriores de este texto. Agradezco a Sally Merry y a Frances Olsen por las conversaciones sobre violencia contra las mujeres y sobre algunas ideas que fueron desarrolladas en este artículo. También agradezco a Joseph Doherty sus enseñanzas sobre métodos empíricos y su apoyo en el análisis de la información cuantitativa en esta investigación. Agradezco a la Fiscalía General de la Nación y al Instituto Nacional Penitenciario y Carcelario por la información estadística oficial que me entregaron para realizar mi análisis cuantitativo. Así mismo, agradezco a la Corporación Excelencia en la Justicia, en particular, a su directora Gloria María Borrero por su generosidad al compartir información de su base de datos. Finalmente, agradezco a los funcionarios y abogados a quienes entrevisté durante esta investigación por su paciencia con mis interminables cuestionarios y sus valiosos aportes.

** Profesora asistente, Facultad de Ciencias Jurídicas, Pontificia Universidad Javeriana. Doctora en derecho (SJD), Universidad de California, Los Ángeles, UCLA. Magíster en derecho con énfasis en teoría del derecho, Universidad de Nueva York, NYU. Magíster en derecho, Universidad de los Andes. Abogada, Pontificia Universidad Javeriana. Contacto: astrid.sanchez@javeriana.edu.co 


\section{RESUMEN}

Este estudio examina cómo los actores que promueven agendas de justicia restaurativa y agendas punitivas han competido en la definición de medidas para enfrentar la violencia intrafamiliar en el contexto del Código de Procedimiento Penal de 2004. En los últimos años, las agendas punitivas han ganado en el contexto de las reformas legales. Medidas enfocadas en el control de criminalidad y la sanción penal se han ofrecido como respuesta a la subordinación de la mujer y la violencia contra las mujeres dentro de la familia. Este artículo evalúa algunas de las consecuencias de la expedición de las medidas de control de la criminalidad para enfrentar la violencia intrafamiliar. Presentando datos cuantitativos y cualitativos, concluyo que la eficacia del enfoque punitivo frente a este tipo de violencia es discutible. A pesar de que el encarcelamiento por violencia intrafamiliar ha aumentado, sigue siendo bastante bajo en relación con otros delitos. El enfoque punitivo también puede haber tenido el resultado no deseado de alienar a algunas víctimas del proceso penal y desanimar a otras de cooperar con los fiscales. Estos resultados mixtos indican que los defensores de las mujeres deben tener cuidado con la promoción de estrategias punitivas para hacer frente a la violencia intrafamiliar.

Palabras clave: violencia intrafamiliar; justicia restaurativa; punitivismo; derechos de las mujeres 


\section{ABSTRACT}

This study examines how actors promoting restorative justice agendas and punitive agendas have competed for defining measures to deal with domestic violence in the context of the 2004 Criminal Procedure Code. In recent years, punitive agendas have won in the competition to affect legal reform. Criminal sanction and crime control measures have been offered in response to the subordination of women and to violence against women within the family. This article assesses some of the consequences of the enactment of crime control measures to face domestic violence. Providing quantitative and qualitative data, I conclude that the effectiveness of the punitive approach to this form of violence is debatable. Although imprisonment for domestic violence has increased, it remains quite low in relation to other offenses. The punitive approach may have also had the unintended result of alienating some victims from the criminal process and discouraging others from cooperating with prosecutors. These mixed results indicate that women's advocates should be cautious about promoting punitive strategies to deal with domestic violence.

Keywords: domestic violence; restorative justice; punitivism; women's rights

\section{SUMARIO}

InTRODUCCIÓN.- DATOS.- ORGANIZACIÓN DE ESTE ARTículo.- I. EstadísticAS BÁsicas SOBRe víctimas de VIF en Colombia.- A. Caracterización de las víctimas de violencia intrafamiliar.- $B$. El subregistro de la violencia contra las mujeres, VCM.- II. VIOLENCIA INTRAFAMILIAR Y JUSTICIA RESTAURATIVA EN EL CPP DE 2004.- $A$. La agenda de justicia restaurativa en el CPP de 2004.- B. La violencia intrafamiliar como un delito menor en el CPP de 2004.- C. El uso extensivo de la conciliación para abordar la VIF y sus fallas.- III. LAS CONTRARREFORMAS PUNITIVAS AL CPP DE 2004 PARA COMBatir la violencia intrafamiliar.- $A$. Aumento de las penas de prisión y establecimiento de la detención preventiva para los casos de VIF.- B. La violencia intrafamiliar: alternando períodos de delito de oficio y delito querellable.- C. El impacto de las contrarreformas punitivas al CPP de 2004.- IV. VIOLENCIA INTRAFAMILIAR: ENTRE UN ENFOQUE PUNITIVO Y UN ENFOQUe DE JUSTiCia RESTAURATIVA.- Conclusiones.- Bibliografía. 


\section{INTRODUCCIÓN}

La violencia doméstica o violencia intrafamiliar (en lo sucesivo, VIF) es un fenómeno global que perpetúa la desigualdad de género y la subordinación de las mujeres ${ }^{1}$. En Colombia, los defensores de los derechos de las mujeres han utilizado estrategias de reforma legal que incluyen diversos enfoques para combatir este tipo de violencia. Los principales enfoques han sido: i) castigo penal, ii) seguridad y asistencia para las víctimas, y iii) transformación de las percepciones individuales y sociales frente a la violencia contra las mujeres (en lo sucesivo, VCM). Sin embargo, las estrategias punitivas han tenido un papel dominante en las agendas de muchas de las organizaciones de mujeres.

A mediados de la década de los 90, los defensores de los derechos de las mujeres promovieron provisiones constitucionales y proyectos de ley para garantizar su derecho a una vida libre de violencia. En particular, el movimiento de mujeres logró la inclusión de la VIF en el artículo 42 constitucional $^{2}$ y la expedición de la Ley 294 de $1996^{3}$ que tipifica la VIF como delito autónomo. Los objetivos de

1 Aunque algunos hombres también son victimizados, las tasas de mujeres víctimas de violencia doméstica son desproporcionadamente altas. La violencia contra las mujeres en el hogar está relacionada con patrones de matrimonio y concepciones de autoridad masculina y sumisión femenina. Sally Engle Merry, Gender Violence: A Cultural Perspective, 1 (Wiley-Blackwell, Hoboken, New Jersey, 2009).

2 "Cualquier forma de violencia en la familia se considera destructiva de su armonía y unidad, y será sancionada conforme a la ley". Colombia, Constitución Política, 116 Gaceta Constitucional, 20 de julio de 1991, artículo 42, inciso 5. Segunda edición corregida disponible en: http://www.secretariasenado.gov.co/senado/basedoc/constitucion_politica_1991.html

3 En 1995, activistas de la organización no gubernamental Casa de la Mujer redactaron un proyecto de ley sobre VIF para lograr la materialización del artículo 42 de la Constitución de 1991. La senadora Piedad Córdoba presentó este proyecto de ley al Congreso y los grupos feministas y las organizaciones de mujeres abogaron por la aprobación de este proyecto de ley que se convirtió en la Ley 294 de 1996. Esta ley fue el primer paso legislativo para combatir la VIF, mediante la creación de la VIF como delito específico con pena de prisión, medidas para proteger a las víctimas y programas de educación para los agresores. NADIA CoNSTANZA LóPEZ-TÉLLEZ, Violencias contra las mujeres: presencias institucionales, movilizaciones sociales y prácticas legislativas. El caso de la incidencia feminista para el logro de la Ley contra la Violencia hacia las Mujeres, 244 (Tesis de maestría en estudios políticos y relaciones internacionales, Universidad Nacional de Colombia, Bogotá, 2009). Disponible en: http://www.bdigital.unal. edu.co/2433/1/nadialopeztellez.2009.pdf. María Emma Wills, Inclusión sin representación: la irrupción política de las mujeres en Colombia 1970-2000 (Editorial Norma, Bogotá, 2007). Colombia, Ley 294 de 1996, por la cual se desarrolla el artículo 42 de la Constitución Política y se dictan normas para prevenir, remediar y sancionar la violencia intrafamiliar, 42.836 Diario Oficial, 22 de julio de 1996. Disponible en: http://www.secretariasenado.gov.co/senado/ basedoc/ley_0294_1996.html. La Ley 575 de 2000 reformó parcialmente la Ley 294 de 1996 (Ley de VIF). La senadora Piedad Zuccardi promovió esta reforma como respuesta a las quejas 
esta legislación eran transformar las concepciones problemáticas que justifican o trivializan la VIF, y lograr la investigación y sanción de este tipo de violencia en la justicia penal.

En el contexto del Código de Procedimiento Penal de 2004 (en lo sucesivo CPP de 2004), los actores que promueven agendas de justicia restaurativa y agendas punitivas han competido en la definición de medidas para abordar la VIF en la justicia penal. Los defensores de la agenda punitiva confían en la sanción penal como respuesta central a la delincuencia y los problemas sociales; en este caso, a la subordinación de las mujeres. Por el contrario, la agenda de justicia restaurativa resalta la prevención y reparación del delito.

En el CPP de 2004, prevaleció un enfoque de justicia restaurativa en teoría. Este Código estableció la VIF como un delito menor - delito querellable -; por ello, impuso como obligatoria la conciliación preprocesal como mecanismo de justicia restaurativa. Adicionalmente, la detención preventiva era inaplicable. En consecuencia, la conciliación se mantuvo como la respuesta predominante del Estado a la VIF y los agresores no eran enviados a prisión.

Teniendo en cuenta la regulación de la VIF como un delito menor y las fallas en la implementación de la conciliación, los defensores de los derechos de la mujer han articulado estrategias de reforma legal para complementar y contrarreformar el CPP de 2004. La Ley

de los jueces sobre la congestión judicial generada por los casos de VIF. Así, la Ley 575 de 2000 eliminó algunas responsabilidades de los funcionarios judiciales al enfrentar este tipo de violencia. Esta reforma legislativa atribuyó a autoridades administrativas (Comisarías de Familia) la facultad de dictar medidas de protección para las víctimas y estableció mecanismos alternativos de solución de conflictos (MASC) para manejar estos casos, como la conciliación en equidad y los jueces de paz. Grupos de mujeres y organizaciones feministas y de derechos humanos denunciaron que la Ley 575 de 2000 retrocedió en los avances logrados por la Ley 294 de 1996, y que las medidas adoptadas por esta nueva ley subestimaban y perpetuaban la VCM. Carolina Báez, Cecilia Barraza, Nathalia Buenahora, luz Piedad Caicedo \& CAROLINA LóPEZ, La situación de las mujeres víctimas de violencias de género en el sistema penal acusatorio, 32, 33 (Serie Acceso a la Justicia, 1, Corporación Humanas, Centro Regional de Derechos Humanos y Justicia de Género, Bogotá, 2008). Disponible en: http://www.bdigital. unal.edu.co/45466/. NAdia ConstanZa LóPEZ-TélLEz, Violencias contra las mujeres: presencias institucionales, movilizaciones sociales y prácticas legislativas. El caso de la incidencia feminista para el logro de la Ley contra la Violencia hacia las Mujeres, 58 (Tesis de maestría en estudios políticos y relaciones internacionales, Universidad Nacional de Colombia, Bogotá, 2009). Disponible en: http://www.bdigital.unal.edu.co/2433/1/nadialopeztellez.2009.pdf. Colombia, Ley 575 de 2000, por medio de la cual se reforma parcialmente la Ley 294 de 1996, 43.889 Diario Oficial, 11 de febrero de 2000. Disponible en: http://www.secretariasenado.gov.co/ senado/basedoc/ley_0575_2000.html

4 Colombia, Ley 906 de 2004, por la cual se expide el Código de Procedimiento Penal de 2004, 45.658 Diario Oficial, 1 de septiembre de 2004. Disponible en: http://www.secretariasenado. gov.co/senado/basedoc/ley_0906_2004.html 


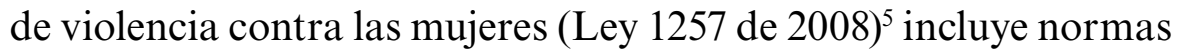
internacionales sobre derechos de las mujeres y medidas para la asistencia y protección de las víctimas. Uno de los objetivos era incorporar una perspectiva de género y derechos específicos de las mujeres en el proceso penal. Los defensores de los derechos de las mujeres también han promovido una serie de reformas del CPP de 2004 para fomentar la persecución penal más activa y el uso de la prisión para sancionar la VIF. Las Leyes 1142 de $2007^{6}$ y 1542 de $2012^{7}$ adoptaron un enfoque punitivo frente a los derechos de la mujer. En estas leyes, feministas y defensores de los derechos de las mujeres tuvieron éxito al lograr la eliminación de la conciliación, el aumento de las penas de prisión y la ampliación de la detención preventiva para la violencia perpetrada dentro de la familia.

La cuestión central en este artículo es si los defensores de los derechos de las mujeres han alcanzado sus objetivos en relación con el enjuiciamiento y la condena de la VIF. Este análisis sobre las reformas punitivas para combatir la VIF, en particular la Ley 1542 de 2012, tiene limitaciones. Es demasiado pronto para sacar conclusiones definitivas sobre los efectos de esta reforma legal, ya que es muy reciente y, por lo tanto, los datos disponibles representan solo unos pocos años.

A pesar de estas limitaciones, los datos sugieren con firmeza que el movimiento de mujeres ha logrado algunos de sus objetivos con respecto al control de criminalidad y el castigo de los agresores. Sin embargo, este éxito se ve mitigado por el hecho de que solo un pequeño porcentaje de los agresores está siendo condenado y castigado, y parece que la regulación punitiva desincentiva a las mujeres para buscar ayuda institucional, presentar quejas y cooperar con

5 Colombia, Ley 1257 de 2008, por la cual se dictan normas de sensibilización, prevención y sanción de formas de violencia y discriminación contra las mujeres, se reforman los Códigos Penal, de Procedimiento Penal, la Ley 294 de 1996 y se dictan otras disposiciones, 47.193 Diario Oficial, 4 de diciembre de 2008. Disponible en: http://www.secretariasenado.gov.co/ senado/basedoc/ley_1257_2008.html

6 Colombia, Ley 1142 de 2007, por medio de la cual se reforman parcialmente las Leyes 906 de 2004, 599 de 2000 y 600 de 2000 y se adoptan medidas para la prevención y represión de la actividad delictiva de especial impacto para la convivencia y seguridad ciudadana, 46.673 Diario Oficial, 28 de julio de 2007. Disponible en: http://www.secretariasenado.gov.co/senado/ basedoc/ley_1142_2007.html

7 Colombia, Ley 1542 de 2012, por la cual se reforma el artículo 74 de la Ley 906 de 2004, Código de Procedimiento Penal, 48.482 Diario Oficial, 5 de julio de 2012. Disponible en: http://www. secretariasenado.gov.co/senado/basedoc/ley_1542_2012.html 
los fiscales. Estos resultados mixtos indican que los defensores de las mujeres deben ser cuidadosos con la promoción de estrategias principalmente punitivas para hacer frente a la VIF.

\section{Datos}

Este artículo comprende un análisis empírico que incluye datos cuantitativos y cualitativos. Parte de un trabajo de campo llevado a cabo en Bogotá entre mayo y agosto de 2014. Consulté informes sobre el sistema de justicia penal publicados por organizaciones no gubernamentales e instituciones del Estado. También llevé a cabo veinticinco entrevistas semiestructuradas con abogados, defensores de mujeres, autoridades estatales, fiscales y jueces. Para las entrevistas, elegí actores con diferentes aproximaciones utilizando muestreo de bola de nieve. Estas entrevistas variaron en duración de treinta minutos a más de dos horas, algunas fueron grabadas ${ }^{8}$.

Adicionalmente, analicé información estadística oficial sobre la operación del sistema de justicia criminal. La Policía Nacional genera datos sobre delitos reportados y capturas en la Revista Criminalidad ${ }^{9}$. El Instituto Nacional de Medicina Legal y Ciencias Forenses, INML, presenta datos sobre casos examinados y caracterización de las víctimas de VIF mediante Forensis ${ }^{10}$. El Instituto Nacional Penitenciario y Carcelario (INPEC) me entregó una base de datos sobre población penitenciaria desde 1990; esta incluye detalles sobre delitos por los que ingresan los internos y características socioeconómicas de los internos desde 2000 a 2015. La Corporación Excelencia en la Justicia y la Fiscalía General de la Nación me suministraron datos sobre procesamientos y condenas bajo el CPP de

8 No entrevisté víctimas, lo que refleja mi elección al definir el alcance de mi investigación. Mi estudio no es sobre las experiencias de las mujeres víctimas de la violencia en el sistema de justicia penal. Esta investigación se limitó a analizar la producción, interpretación y aplicación de las normas e instituciones en relación con el enjuiciamiento y condena de la VIF. Las conclusiones de este artículo sugieren la necesidad de investigación adicional para desarrollar una mejor comprensión de los efectos de las reformas a la justicia penal en la protección de los derechos de las mujeres víctimas, las experiencias de las víctimas que participan en los procesos penales, y los deseos y preferencias de diferentes grupos de víctimas con respecto a las respuestas a la delincuencia.

9 Policía Nacional de Colombia, Revista Criminalidad. Disponible en: http://www.policia.gov. co/portal/page/portal/HOME/publicaciones/revista_criminalidad/pub

10 Instituto Nacional de Medicina Legal y Ciencias Forenses, INML, Forensis. Disponible en: http://www.medicinalegal.gov.co/en/forensis1;jsessionid=D97E6C23C6AF27539AFAE237F1 220E3D 
$2004^{11}$, pero esta información tiene algunas limitaciones. Aunque parece que el sistema de información de la Fiscalía General de la Nación (Sistema Penal Oral Acusatorio, SPOA) está mejorando después de la reforma que adoptó un sistema penal acusatorio en la primera década del siglo XXI, las prácticas para los reportes y las unidades de análisis han cambiado muchas veces después de la reforma. Por lo tanto, no en todos los casos está disponible información estadística coherente y comparable que abarque todo el período de estudio ${ }^{12}$. A pesar de estas limitaciones de los datos cuantitativos, como muestra el análisis presentado a continuación, las estadísticas disponibles permiten explorar si los defensores de los derechos de las mujeres han alcanzado sus objetivos en relación con el procesamiento penal y la condena de la VIF.

\section{Organización de este artículo}

Este artículo está organizado de la siguiente manera: La sección I proporciona estadísticas básicas sobre la VIF en Colombia. La sección II sugiere que el CPP de 2004 reguló esta forma de violencia como un delito menor. Esta sección analiza brevemente la agenda de justicia restaurativa promovida en el contexto del CPP de 2004 y la obligación de participar en una audiencia de conciliación preprocesal en los casos de VIF. Además, esta explora la aplicación de la conciliación en casos de VIF en el marco del CPP de 2004 y sus fallas - antes de la eliminación de la conciliación preprocesal obligatoria mediante la Ley 1542 de 2012 - . La sección III evalúa las estrategias de defensores de las mujeres para complementar y contrarreformar el CPP de 2004 para enfrentar la VIF. En particular, esta sección analiza las contrarreformas punitivas al CPP de 2004 en cuanto al tratamiento de la VIF. Esta sección también examina

11 Presenté un derecho de petición al Consejo Superior de la Judicatura solicitando información en 2014, pero aún no he obtenido respuesta.

12 La Comisión Asesora de Política Criminal señala algunos problemas de los sistemas de información sobre la justicia penal, como las deficiencias en la consistencia y comparabilidad de los datos, la falta de información desagregada para analizar el impacto del sistema de justicia penal en las poblaciones vulnerables y la desarticulación de los sistemas de la información. Colombia, Comisión Asesora de Política Criminal, Informe final. Diagnóstico y propuesta de lineamientos de politica criminal para el Estado colombiano, 30 (Ministerio de Justicia y del Derecho, Agencia Presidencial de Cooperación Internacional de Colombia, APC Colombia, Unión Europea, Bogotá, 2012). Disponible en: https://www.minjusticia.gov.co/Portals/0/ INFO $\% 20$ POLI $\% 20$ CRIMINAL_FINAL23NOV.pdf 
los efectos de las medidas de control de criminalidad aprobadas por la Ley 1142 de 2007 y las reformas para lograr el procesamiento penal más activo de la VIF establecidas por la Ley 1542 de 2012. Finalmente, la sección IV discute la competencia entre la justicia restaurativa y los enfoques punitivos para abordar la VIF en la justicia penal.

\section{ESTADÍSTICAS BÁSICAS SOBRE VÍCTIMAS DE VIF EN COLOMBIA}

\section{A. Caracterización de las víctimas de violencia intrafamiliar}

En 2014, el Instituto Nacional de Medicina Legal y Ciencias Forenses, INML, examinó 75.939 víctimas de violencia dentro de la familia. Entre 2000 y 2014, la tasa de VIF por cada 100.000 habitantes permaneció alta; la tasa media fue 174,34 y la tasa promedio fue 176,96. Sin embargo, esta tasa disminuyó en dos períodos (2002-2004 y 2010-2013).

La tasa de VIF por cada 100.000 habitantes se redujo de 171 por 100.000 en 2001 a 142 por 100.000 en 2004. Una posible explicación de esta disminución fue la transferencia de ciertas funciones de jueces y fiscales a los comisarios de familia en la Ley 575 de 2000. De acuerdo con esta ley, los comisarios de familia conocían muchos casos de VIF mediante un procedimiento administrativo.

Después de un aumento constante de la tasa de VIF por cada 100.000 habitantes entre 2004 y 2009 , esta tasa se redujo de nuevo entre 2010 y 2013. En 2013, la tasa de VIF por 100.000 habitantes fue 144,78 (68.230 víctimas). Esta tasa fue $30 \%$ menor que su pico de 209 por 100.000 habitantes en 2009 y 15\% menos que la tasa de 2000 (gráfico 1). De 2013 a 2014, la tasa de VIF por 100.000 habitantes se incrementó en un 10\%, de 144,79 en 2013 a 159,32 en 2014. Esta última fue $24 \%$ menor que su pico de 209 en 2009 y $6 \%$ por debajo de la tasa de 2000. Estos datos no indican que los actos de VIF hayan disminuido en el país. Al final de la siguiente sección, argumentaré que la adopción de medidas de control de criminalidad para enfrentar la VIF contribuye a explicar esta disminución en los casos registrados por el INML. 


\section{Gráfico 1}

VIF En Colombia (2000-2014)

Casos de VIF y tasa por cada 100.000 habitantes

Casos de VIF con mujeres víctimas y tasa de mujeres víctimas por 100.000 mujeres habitantes

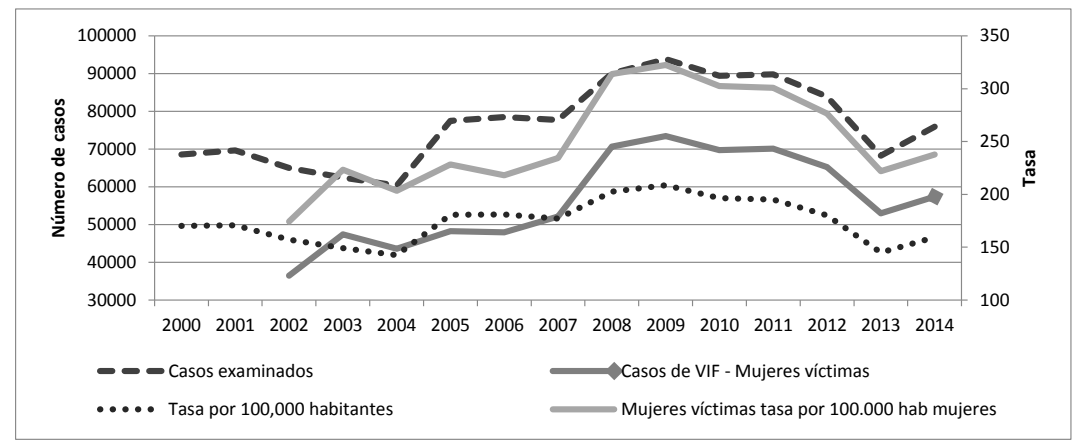

Fuente: Instituto Nacional de Medicina Legal y Ciencias Forenses, INML, Forensis 2000-2014

La VIF es un mecanismo de control y poder masculino que reproduce la subordinación de las mujeres. De acuerdo con los datos de los exámenes forenses de las víctimas de VIF practicados por el INML, las mujeres experimentaron la tasa de victimización más alta. Entre 2002 y 2014, la tasa media de las mujeres víctimas era 250 por cada 100.000 mujeres (gráfico 1). De 2003 a 2014, el 78\% de las víctimas de VIF correspondía al sexo femenino. En 2014, el INML examinó 57.372 mujeres víctimas de este tipo de violencia (la tasa por 100.000 mujeres fue 238).

Entre 2003 y 2014, el 63\% de los casos de VIF correspondía a violencia de pareja. En las encuestas nacionales de demografía y salud, las mujeres que habían estado en una relación íntima reportaron altos niveles de abuso emocional. Un gran porcentaje de las mujeres también reportó violencia física. En 2010, el 9,70\% de las mujeres reportó haber experimentado agresiones sexuales como forma de violencia dentro de la familia (tabla 1). 
Tabla 1

Violencia de pareja: formas de violencia $(2000,2005,2010)$

\begin{tabular}{|l|l|l|l|l|}
\hline & & $\begin{array}{l}\text { ENDS } \\
\text { 2000 (\%) }\end{array}$ & $\begin{array}{l}\text { ENDS } \\
\text { 2005 (\%) }\end{array}$ & $\begin{array}{l}\text { ENDS } \\
2010(\%)\end{array}$ \\
\hline \multirow{2}{*}{$\begin{array}{l}\text { Violencia } \\
\text { verbal }\end{array}$} & $\begin{array}{l}\text { Esposo o compañero } \\
\text { ejerce control }\end{array}$ & 64,9 & 65,7 & 65,3 \\
\cline { 2 - 5 } & $\begin{array}{l}\text { Esposo o compañero usa } \\
\text { expresiones desobligantes }\end{array}$ & 26,2 & 26,3 & 26,1 \\
\cline { 2 - 5 } & $\begin{array}{l}\text { Esposo o compañero } \\
\text { amenaza }\end{array}$ & 33,8 & 32,6 & 32,0 \\
\hline $\begin{array}{l}\text { Violencia } \\
\text { física }\end{array}$ & $\begin{array}{l}\text { Mujeres alguna vez } \\
\text { casadas o unidas víctimas } \\
\text { de violencia por parte del } \\
\text { esposo o compañero }\end{array}$ & 41,1 & 39,0 & 37,4 \\
\hline $\begin{array}{l}\text { Violencia } \\
\text { sexual }\end{array}$ & $\begin{array}{l}\text { El autor es el esposo o } \\
\text { compañero permanente }\end{array}$ & 11,0 & 11,5 & 9,70 \\
\hline
\end{tabular}

Fuente: Profamilia $(2000,2005,2010)$. Encuesta Nacional de Demografí y Salud, ENDS ${ }^{13}$

La mayoría de las mujeres víctimas tenía un estatus socioeconómico bajo, teniendo en cuenta su edad y nivel de estudios ${ }^{14}$. Entre 2000 y 2013, las mujeres de 20 años o más experimentaron mayores tasas de VIF (89\% de los casos). La mayoría de las mujeres víctimas tenía niveles bajos de educación. El 24\% tenía educación primaria, el 55\% tenía educación secundaria, el 8\% tenía educación técnica y el 7\% obtuvo un título profesional. Un menor nivel socioeconómico limita la capacidad de las mujeres víctimas para escapar o resistirse a la violencia, ya que las desigualdades estructurales (por ejemplo, la clase y el género) afectan sus opciones ${ }^{15}$. Hay que resaltar que

13 Profamilia (2000, 2005, 2010). Encuesta Nacional de Demografía y Salud, ENDS. Disponible en: http://profamilia.org.co/investigaciones/ends/

14 Teniendo en cuenta que la mayoría de las mujeres víctimas de la VIF son mayores de 20 años, el nivel de instrucción puede ser una variable proxy de su nivel socioeconómico (SES).

"La educación es quizás el aspecto más fundamental de SES. Los niveles más altos de educación se asocian con mejores resultados económicos (por ejemplo, probabilidad de empleo, ingresos, menos dificultad financiera), más recursos sociales y psicológicos (por ejemplo, una mayor sensación de control, más apoyo social)". American Psychological Association, APA, Report of the APA Task Force on Socioeconomic Status, 9 (American Psychological Association, APA, Task Force on Socioeconomic Status, Washington, 2007). Disponible en: https:// www.apa.org/pi/ses/resources/publications/task-force-2006.pdf

15 Sally Engle Merry, Gender Violence: A Cultural Perspective (Wiley-Blackwell, Hoboken, New Jersey, 2009). James PtaceK, Battered Women in the Courtroom: The Power of Judicial 
el acceso a la justicia y a asistencia integral — legal, psicológica, social y médica- depende en gran medida de la situación socioeconómica de la víctima ${ }^{16}$.

\section{B. E1 subregistro de la violencia contra las mujeres (VCM)}

Es difícil medir la frecuencia real de la VCM, debido a que un alto porcentaje de víctimas NO reporta haber experimentado violencia. De acuerdo con la Encuesta Nacional de Demografía y Salud, ENDS, de 2010, el 72,70\% de las mujeres entrevistadas que sufrieron violencia dijo no haber acudido a una institución estatal en busca de ayuda. Este porcentaje de abusos no denunciados ha disminuido ligeramente desde el año 2000. En la ENDS de 2000, el $78,2 \%$ de las mujeres encuestadas dijo no haber buscado ayuda institucional; en la ENDS de 2005, el 76,1\% de las mujeres señaló no haber acudido a las instituciones estatales.

La ENDS también muestra por qué un alto porcentaje de mujeres víctimas no denuncia (tabla 2). Muchas mujeres no interpretan un incidente violento como un abuso. Sin embargo, en la ENDS de 2010, menos mujeres respondieron que piensan que el abuso es parte de la vida ordinaria o que lo merecen. Además, la capacidad de algunas mujeres para resistir o escapar de la violencia es limitada. Otras temen represalias por denunciar. Por último, algunas mujeres deciden no reportar su caso, porque tienen una opinión negativa del sistema de justicia penal. Los porcentajes de mujeres que no buscan ayuda por miedo a la venganza o por la falta de confianza en el sistema judicial han aumentado ligeramente. Esto

Responses (Northeastern Series on Gender, Crime and Law, Northeastern University Press, Lebanon, New Hampshire, 1999).

16 Entrevista con una abogada de la Secretaría Distrital de la Mujer de Bogotá, 28 de julio de 2014. Del mismo modo, "la CIDH ha constatado la gran divergencia que existe entre el acceso a la justicia por parte de mujeres que tienen recursos económicos y las que se encuentran en desventaja económica". Organization of American States, OAS, Inter-American Commission on Human Rights, IACHR (Organización de los Estados Americanos, OEA, Comisión Interamericana de Derechos Humanos, CIDH), Access to Justice for Women Victims of Violence in the Americas, OEA/Ser.L/V/II, Doc. 68, 20 January 2007, párr. 184 (Organization of American States, OAS, Inter-American Commission on Human Rights, CIDH, Washington, 2007). Disponible en: https://www.cidh.oas.org/women/Access07/Report $\% 20$ Access $\% 20$ to $\% 20 J u s t i c e \% 20$ Report $\% 20$ English\%20020507.pdf, http://www.cidh.oas.org/pdf\%20files/ Informe $\% 20$ Acceso $\% 20 \mathrm{a} \% 201 \mathrm{a} \% 20 \mathrm{Justicia} \% 20$ Espanol $\% 20020507$.pdf 
puede sugerir que las recientes reformas legales no han mejorado significativamente la situación de las mujeres víctimas de violencia en la justicia penal.

\section{Tabla 2}

Razones para no buscar ayuda institucional (2000, 2005 y 2010)

\begin{tabular}{|l|l|l|l|}
\hline & $\begin{array}{l}\text { ENDS } \\
2000(\%)\end{array}$ & $\begin{array}{l}\text { ENDS } \\
2005(\%)\end{array}$ & $\begin{array}{l}\text { ENDS } \\
2010(\%)\end{array}$ \\
\hline No sabe dónde ir & 4,40 & 6,90 & 10,30 \\
\hline Vergüenza & 7,40 & 5,30 & 13,10 \\
\hline Parte de la vida normal & 9,00 & 8,60 & 6,70 \\
\hline Siente que merece abuso & 7,00 & 5,50 & 2,40 \\
\hline Miedo a la separación & 5,10 & 5,40 & 5,70 \\
\hline Miedo a más agresión & 14,00 & 16,10 & 16,90 \\
\hline Daños no serios & 28,00 & 23,90 & 17,80 \\
\hline No desea dañar al agresor & 14,60 & 13,30 & 10,10 \\
\hline $\begin{array}{l}\text { Cree que puede resolver el problema } \\
\text { sola }\end{array}$ & 14,20 & 24,40 & 30,90 \\
\hline No cree en la justicia & 3,40 & 3,20 & 4,00 \\
\hline Experiencia negativa con la denuncia & 1,00 & 1,00 & 0,50 \\
\hline Cree que no vuelve a ocurrir & 9,20 & 9,30 & 7,00 \\
\hline Aún quiere al agresor & --- & --- & 3,20 \\
\hline
\end{tabular}

Fuente: Profamilia (2000, 2005, 2010). Encuesta Nacional de Demografía y Salud, ENDS ${ }^{17}$

Algunos estudios han documentado razones adicionales por las que las mujeres víctimas no denuncian la violencia: el impacto psicológico causado por el delito; la falta de conocimiento de sus derechos y los procedimientos legales; la falta de recursos financieros; la percepción de impunidad generalizada de la VCM; el miedo a la estigmatización social o a la exclusión; el temor a la revictimización en el sistema judicial; el temor de causar conflictos familiares; $\mathrm{y}$ - en los casos en que un niño es concebido durante

17 Profamilia (2000, 2005, 2010). Encuesta Nacional de Demografía y Salud, ENDS. Disponible en: http://profamilia.org.co/investigaciones/ends/ 
una violación - el miedo a que el niño se entere de las condiciones de su concepción ${ }^{18}$.

Las víctimas en zonas rurales enfrentan obstáculos adicionales para el acceso a la justicia y a asistencia integral. Las víctimas en zonas rurales experimentan aislamiento y falta de recursos. Las oportunidades de asistencia médica, psicológica y legal son limitadas o inexistentes. Adicionalmente, estas víctimas viven en comunidades conservadoras, en las cuales las víctimas de violación pueden ser estigmatizadas o culpadas y la VIF puede ser tolerada ${ }^{19}$. Por estas razones, la mayoría de los actos de violencia cometidos en áreas rurales no se denuncia. Los datos del Instituto Nacional de Medicina Legal y Ciencias Forenses, INML, muestran una amplia variación en la tasa de casos de VCM entre las zonas rurales y urbanas. De acuerdo con el INML, solo el 6,75\% de los abusos de VIF registrados se cometió en zonas rurales en 2013. Este pequeño porcentaje de casos notificados en zonas rurales puede ser una consecuencia de los desafíos que enfrentan las mujeres en esas zonas.

\section{VIOLENCIA INTRAFAMILIAR Y JUSTICIA RESTAURATIVA EN EL CPP DE 2004}

Teniendo en cuenta la alta frecuencia de la VIF y la gravedad de sus consecuencias, el movimiento de mujeres ha promovido la criminalización de la VIF. Como resultado de los primeros esfuerzos, la Constitución de 1991 establece que la VIF debe ser sancionada y la Ley 294 de 1996 tipifica la VIF como un delito autónomo. Una vez que el movimiento de mujeres logró la penalización de la VIF,

18 Carolina Báez, Cecilia Barraza, Nathalia Buenahora, luz Piedad Caicedo \& Carolina LÓPEZ, La situación de las mujeres víctimas de violencias de género en el sistema penal acusatorio (Serie Acceso a la Justicia, 1, Corporación Humanas, Centro Regional de Derechos Humanos y Justicia de Género, Bogotá, 2008). Disponible en: http://www.bdigital.unal.edu.co/45466/. Alexandra Quintero-Benavides, Derechos en Femenino ¿Hacia un real camino a la igualdad? VI Informe de Derechos Humanos de las Mujeres, 2010-2012 (Corporación Sisma Mujer, Red Nacional de Mujeres, Bogotá, 2013). Disponible en: http://www.justiciaypazcolombia.com/ IMG/pdf/vi_informe_ddhh_de_las_mujeres_-derechos_en_femenino.pdf. Sisma Mujer, Obstáculos para el acceso a la justicia de mujeres víctimas de violencia sexual en Colombia (2011).

19 Susan H. Lewis, Unspoken Crimes: Sexual Assault in Rural America (National Sexual Violence Resource Center, NSVRC, Enola, Pennsylvania, 2003). Disponible en: http://www.nsvrc.org/ sites/default/files/Publications_NSVRC_Booklets_Unspoken-Crimes-Sexual-Assault-inRural-America\%20.pdf. World Health Organization, WHO Multi-Country Study on Women's Health and Domestic Violence against Women: Summary Report of Initial Results on Prevalence, Health Outcomes and Women's Responses (2005). 
los defensores y activistas empezaron a exigir que esta forma de violencia se considerara como un delito grave ${ }^{20}$.

A pesar de estos esfuerzos, la violencia que tiene lugar dentro de la familia ha sido tratada como un delito menor en Colombia. Desde la incorporación de la VIF en la Ley 294 de 1996, la respuesta predominante del Estado frente a esta forma de violencia era la conciliación (hasta la eliminación de la conciliación obligatoria por la Ley 1542 de 2012) ${ }^{21}$. El CPP de 2004 siguió la tendencia de regular la VIF como un delito menor y estableció la obligación de participar en una conciliación preprocesal como requisito de procedibilidad. En la siguiente sección, analizo brevemente la agenda de justicia restaurativa promovida en el CPP de 2004, con el fin de proporcionar un contexto para analizar la aplicación de la conciliación preprocesal obligatoria para los casos de VIF. A continuación,

20 La criminalización de la violencia doméstica o VIF como un delito grave ha sido uno de los objetivos del movimiento feminista global. Sally Engle Merry, Gender Violence: A Cultural Perspective (Wiley-Blackwell, Hoboken, New Jersey, 2009). De hecho, algunos académicos y defensores de los derechos de las mujeres maltratadas han enmarcado la violencia doméstica en términos de delitos reconocidos como muy graves. Por ejemplo, algunos autores y la Relatora Especial sobre la violencia contra las mujeres afirman que la violencia doméstica grave puede constituir tortura o tratos crueles, inhumanos o degradantes. Ver, por ejemplo, CATHARINE MacKinnon, On Torture: A Feminist Perspective on Human Rights, en Human Rights in the Twenty-First Century: A Global Challenge, 21-32 (Kathleen Mahoney \& Paul Mahoney, eds., Kluwer, Norwell, Massachusetts, 1993). Rhonda Copelon, Intimate Terror: Understanding Domestic Violence as Torture, en Human Rights of Women: National and International Perspectives, 116-152 (ReвеCCa J. Cook, ed., University of Pennsylvania Press, Philadelphia, Pennsylvania, 1994). En el mismo sentido, Isabel Marcus sostiene que la violencia doméstica contra las mujeres es una forma de terrorismo en el hogar. Isabel Marcus, Reframing 'Domestic Violence': Terrorism in the Home, en The Public Nature of Private Violence: The Discovery of Domestic Abuse, 11-35 (Martha Fineman \& Roxanne Mykitiuk, eds., Routledge, New York, 1994).

Además, los defensores de los derechos de las mujeres maltratadas han exigido que los representantes de los Estados tomen la violencia doméstica en serio. Ellos han reclamado la persecución penal más activa y el castigo penal de este tipo de violencia. SAlly Engle MerRY, Gender Violence: A Cultural Perspective, 50, 51 (Wiley-Blackwell, Hoboken, New Jersey, 2009). Así, han promovido fuertes medidas de control de criminalidad, como el arresto obligatorio, la persecución penal obligatoria y condenas más severas. Donna WiLls, Domestic Violence: The Case for Aggressive Prosecution, 7 UCLA Women's Law Journal, 173-182 (1996). Disponible en: http://escholarship.org/uc/item/7jq4p3kf. Michelle Madden Dempsey, Prosecuting Domestic Violence: A Philosophical Analysis, 222 (Oxford University Press, Oxford, New York, 2009).

21 Javier Pineda-Duque \& Luisa Otero-Peña, Género, violencia intrafamiliar e intervención pública en Colombia, 17 Revista de Estudios Sociales, 19-31 (2004). Disponible en: https://res. uniandes.edu.co/view.php/341/index.php?id=341. Julieta Lemaitre-RIPOlL, Justicia injusta: una crítica feminista a la conciliación en violencia conyugal, 27 Revista de Derecho Privado, 7398 (2002). Disponible en: https://derechoprivado.uniandes.edu.co/components/com_revista/ archivos/derechoprivado/pri223.pdf. Ana Rico de Alonso, María Cristina Hurtado \& Juan Carlos Alonso, Naturaleza del conflicto en el área de atención de familia (Consejo Superior de la Judicatura, Pontificia Universidad Javeriana, Bogotá, 1999). 
examino la regulación de la VIF como un delito menor en el CPP de 2004. En la parte final, exploro la aplicación de la conciliación en casos de VIF y sus fallas.

\section{A. La agenda de justicia restaurativa en el CPP de 2004}

Uno de los objetivos centrales de la reforma constitucional de 2002 que adoptó un sistema con tendencia acusatoria fue proteger los derechos e intereses de las víctimas y desarrollar programas de justicia restaurativa. Así, el CPP de 2004 reconoció una amplia carta de los derechos de las víctimas e incluyó principios de justicia restaurativa.

Un enfoque de justicia restaurativa promueve la restauración del derecho de las víctimas a su propio conflicto. Esta aproximación critica el derecho penal moderno. Uno de sus principales fundamentos es el argumento propuesto por NiLs CHRISTIE en torno a que las instituciones de justicia penal "les quitan los conflictos" a los $\operatorname{afectados}^{22}$. En el derecho penal moderno, el Estado tiene control sobre los sistemas de castigo y los crímenes son violaciones de un interés jurídico abstracto o de la autoridad del Estado. Por lo tanto, el conflicto entre las partes se convierte en un conflicto entre el infractor y el Estado ${ }^{23}$. Los enfoques tradicionales del procedimiento penal y el castigo se centran en el agresor y marginan a la víctima ${ }^{24}$.

22 Nils Christie, Conflicts as Property, 17 The British Journal of Criminology, 1, 1-15 (1977). JoHN BraithwaIte, Building Legitimacy through Restorative Justice, en Legitimacy and Criminal Justice: International Perspectives, 146-162, 148 (Tom R. TYLER, ed., Russell Sage Foundation, New York, 2007). John Braithwaite, Restorative Justice and a Better Future, 76 The Dalhousie Review, 1, 9-32 (1996). Disponible en: https://dalspace.library.dal.ca/handle/10222/63177, https://dalspace.library.dal.ca/bitstream/handle/10222/63177/dalrev_vol76_iss1_pp9_31.pdf? sequence=1\&isAllowed=y. ANTONIO BERISTAIN, Victimología : nueve palabras clave, 476 (Tirant Lo Blanch, Valencia, 2000). Kent RoAch, Criminology, Four Models of the Criminal Process, 89 The Journal of Criminal Law and Criminology, 2, 671-716, 673 (1999). Disponible en: http:// scholarlycommons.law.northwestern.edu/cgi/viewcontent.cgi?article $=7000 \&$ context $=\mathrm{jclc}$

23 Antonio Beristain, Hoy creamos una nueva ciencia cosmopolita e integradora: la victimología de máximos, después de Auschwitz, 54 Revista Vniversitas, 110, 461-487, 467 (2005). Disponible en: http://revistas.javeriana.edu.co/index.php/vnijuri/article/view/14693/11849. JoHN BraITHWAITE, Restorative Justice and a Better Future, 76 The Dalhousie Review, 1, 9-32 (1996). Disponible en: https://dalspace.library.dal.ca/handle/10222/63177, https:/dalspace.library.dal.ca/bitstream/ handle/10222/63177/dalrev_vol76_iss1_pp9_31.pdf?sequence=1\&isAllowed=y

24 Julio Andrés SAmpedro-Arrubla, Las víctimas y el sistema penal: aproximación al proceso penal desde la victimología, 27, 32-34 (Pontificia Universidad Javeriana, Bogotá, 2010). 
El enfoque de justicia restaurativa se basa en los derechos de las víctimas a la autonomía y la libre determinación, los cuales comprenden el derecho a participar en la decisión de su conflicto ${ }^{25}$. Esta perspectiva busca empoderar a las víctimas, al darles una voz directa en el proceso penal y en otros procedimientos relacionados con el delito ${ }^{26}$. Este modelo está centrado en las víctimas, por ello privilegia sus necesidades, intereses y decisiones ${ }^{27}$.

El ideal de la justicia restaurativa comprende valores como la curación, la disculpa y el perdón ${ }^{28}$. Por lo tanto, este enfoque es no punitivo: enfatiza la prevención del delito y la restauración en lugar de la sanción penal, el enjuiciamiento y el castigo ${ }^{29}$. El modelo de justicia restaurativa busca la restauración de las víctimas, la restauración de los agresores y la restauración de las comunidades ${ }^{30}$. En consecuencia, este modelo involucra a las víctimas, los agresores y las comunidades, y da a las víctimas poder y autonomía para participar en la resolución de conflictos ${ }^{31}$. Algunos académicos señalan que el modelo de justicia restaurativa es adecuado para abordar no solo los delitos pequeños, sino también los crímenes más graves como los crímenes de guerra ${ }^{32}$.

25 Markus Dirk Dubber, Victims in the War on Crime: The Use and Abuse of Victims' Rights, 519 (New York University Press, New York, 2006). Kent Roach, Criminology, Four Models of the Criminal Process, 89 The Journal of Criminal Law and Criminology, 2, 671-716, 709 (1999). Disponible en: http://scholarlycommons.law.northwestern.edu/cgi/viewcontent.cgi? article $=7000 \&$ context $=$ jclc

26 John Braithwaite, Building Legitimacy through Restorative Justice, en Legitimacy and Criminal Justice: International Perspectives, 146-162, 148, 157 (Tom R. TyLer, ed., Russell Sage Foundation, New York, 2007). Markus Dirk Dubber, Victims in the War on Crime: The Use and Abuse of Victims' Rights, 519 (New York University Press, New York, 2006).

27 Kent Roach, Criminology, Four Models of the Criminal Process, 89 The Journal of Criminal Law and Criminology, 2, 671-716, 699, 707, 709 (1999). Disponible en: http://scholarlycommons. law.northwestern.edu/cgi/viewcontent.cgi?article $=7000 \&$ context $=$ jclc

28 John BratthwaIte, Building Legitimacy through Restorative Justice, en Legitimacy and Criminal Justice: International Perspectives, 146-162, 148 (TOM R. TyLER, ed., Russell Sage Foundation, New York, 2007).

29 Kent Roach, Criminology, Four Models of the Criminal Process, 89 The Journal of Criminal Law and Criminology, 2, 671-716, 699, 707, 709 (1999). Disponible en: http://scholarlycommons. law.northwestern.edu/cgi/viewcontent.cgi?article $=7000 \&$ context $=$ jclc

30 John Braithwaite, Restorative Justice: Assessing Optimistic and Pessimistic Accounts, 25 Crime and Justice, 1-127, 6 (1999). Disponible en: https://www.researchgate.net/publication/ 249188069_Restorative_Justice_Assessing_Optimistic_and_Pessimistic_Accounts

31 Kent Roach, Criminology, Four Models of the Criminal Process, 89 The Journal of Criminal Law and Criminology, 2, 671-716, 707, 709, 710 (1999). Disponible en: http://scholarlycommons. law.northwestern.edu/cgi/viewcontent.cgi?article $=7000 \&$ context $=$ jclc

32 John Braithwaite, Restorative Justice: Assessing Optimistic and Pessimistic Accounts, 25 Crime and Justice, 1-127, 7 (1999). Disponible en: https://www.researchgate.net/publication/ 249188069_Restorative_Justice_Assessing_Optimistic_and_Pessimistic_Accounts 
Teniendo en cuenta este marco, el CPP de 2004 (artículo 521) incorpora tres mecanismos de justicia restaurativa: conciliación preprocesal, conciliación en el incidente de reparación integral y mediación. El CPP de 2004 establece la conciliación preprocesal para los delitos querellables como obligatoria y como requisito de procedibilidad $^{33}$. El CPP de 2004 incluye la mediación como un mecanismo nuevo que puede ser implementado para abordar delitos graves ${ }^{34}$. El CPP de 2004 contiene algunas pocas reglas sobre los mecanismos de justicia restaurativa, y establece la obligación para el Fiscal General de desarrollar un manual para regular la mediación y los programas de justicia restaurativa ${ }^{35}$.

\section{B. La violencia intrafamiliar como un delito menor en el CPP de 2004}

El CPP de 2004 estableció la VIF como un delito querellable, siguiendo la tradición de considerar este delito como una ofensa menor. El CPP requiere querella para iniciar la acción penal por las conductas definidas como querellables, excepto si la víctima es menor de edad (artículo 74 CPP). En cualquier momento de la actuación y antes de concluir la audiencia preparatoria, el querellante puede desistir de la querella, es decir, puede manifestar su deseo de no continuar con los procedimientos (artículo $76 \mathrm{CPP}$ ). Así las cosas, la víctima tiene derecho a elegir si el agresor es procesado o no.

33 El Código de Procedimiento Penal ha incluido la conciliación para delitos menores a partir de 1989. Colombia, Decreto 1861 de 1989, por el cual se introducen modificaciones al Código de Procedimiento Penal y se dictan otras disposiciones, artículo 31 bis, 38.945 Diario Oficial, 18 de agosto de 1989. Disponible en: ftp://ftp.camara.gov.co/camara/basedoc/decreto/1989/ decreto_1861_1989.html

34 De acuerdo con la Corporación Excelencia en la Justicia, CEJ, el uso de la mediación es poco frecuente. Por lo tanto, la CEJ sugiere que el Fiscal General adopte estrategias para fortalecer este mecanismo. Corporación Excelencia en la Justicia, Balance de los primeros cinco años de funcionamiento del Sistema Penal Acusatorio en Colombia, 112 (2011). Disponible en: http://www.cej.org.co/index.php/publicaciones/libros/2599-balance-de-los-primeros-cinco-anos-de-funcionamiento-del-sistema-penal-acusatorio-en-colombia

35 La CEJ ha sugerido al Fiscal General que diseñe el manual sobre mediación y programas de justicia restaurativa, de acuerdo con lo ordenado por el CPP de 2004, con el fin de mejorar la implementación de estos mecanismos. Corporación Excelencia en la Justicia, Balance de los primeros cinco años de funcionamiento del Sistema Penal Acusatorio en Colombia, 112 (2011). Disponible en: http://www.cej.org.co/index.php/publicaciones/libros/2599-balancede-los-primeros-cinco-anos-de-funcionamiento-del-sistema-penal-acusatorio-en-colombia. Corporación Excelencia en la Justicia, Balance diez años de funcionamiento del Sistema Penal Acusatorio en Colombia 2004-2014 (2015). Disponible en: http://www.cej.org.co/ 
El CPP de 2004 establecía la obligación de participar en una conciliación preprocesal para los delitos querellables (artículo 522). Si la víctima y el agresor llegan a un acuerdo en la audiencia de conciliación, el fiscal cerraría el caso; de lo contrario, el fiscal iniciaría una acción penal. Es de resaltar que la conciliación siguió siendo el mecanismo predominante para resolver los casos de VIF hasta cuando la Ley 1542 de 2012 eliminó la conciliación obligatoria para abordar este tipo de violencia.

La Ley 1142 de 2007 estableció la VIF como un delito que se persigue de oficio. Sin embargo, esta ley mantuvo los efectos de los delitos querellables como la conciliación preprocesal y el derecho de las víctimas a desistir de la querella ${ }^{36}$. La ley de VCM (Ley 1257 de 2008) reconoció el derecho de las mujeres víctimas a no ser forzadas a confrontar a sus agresores; los defensores de las mujeres promovieron este derecho para prohibir la conciliación. Sin embargo, la ley de VCM no proscribió expresamente la conciliación. Así, la Ley 1142 de 2007 y la Ley de VCM no afectaron sustancialmente las prácticas de los fiscales y el uso extensivo de la conciliación para los casos de VIF.

\section{El uso extensivo de la conciliación para abordar la VIF $y$ sus fallas}

A diferencia de la mayoría de los defensores de las mujeres, muchos funcionarios del Estado preferían la conciliación para tratar los casos de VIF y buscaban preservar la unidad familiar. En una encuesta realizada en 2010, el 97\% de los comisarios de familia y el 94\% de los funcionarios de la Fiscalía General de la Nación señalaron que ellos buscaban que las partes llegaran a un acuerdo en las audiencias de conciliación. Adicionalmente, el 72\% de los comisarios de familia y el $61 \%$ de los funcionarios de la Fiscalía General de la Nación respondieron que ellos favorecían la conciliación y la unidad familiar. Además de eso, el $43 \%$ de los funcionarios del

36 La Corte Constitucional consideró que si bien la exposición de motivos de la Ley 1142 de 2007 propuso la prohibición de la conciliación para la VIF, esta ley no la proscribió. La Corte sostuvo que los casos de VIF podían ser objeto de conciliación, porque era posible aplicar los mecanismos para la terminación anticipada del proceso penal. La Corte aclaró que la aplicación de la conciliación en casos de VIF debía tener en cuenta el interés prevalente del menor y la protección, privacidad y dignidad de la mujer. Corte Constitucional, Sentencia C-1198-08, 4 de diciembre de 2008, magistrado ponente Nilson Pinilla-Pinilla. Disponible en: http://www.corteconstitucional.gov.co/RELATORIA/2008/C-1198-08.htm 
Estado creía que la conciliación era el único mecanismo eficaz para manejar casos de VIF, teniendo en cuenta el alto número de casos por este delito en el sistema ${ }^{37}$.

\section{Gráfico 2}

\section{Conciliaciones/Casos terminados -CPP de 2004 (2005-2011)}

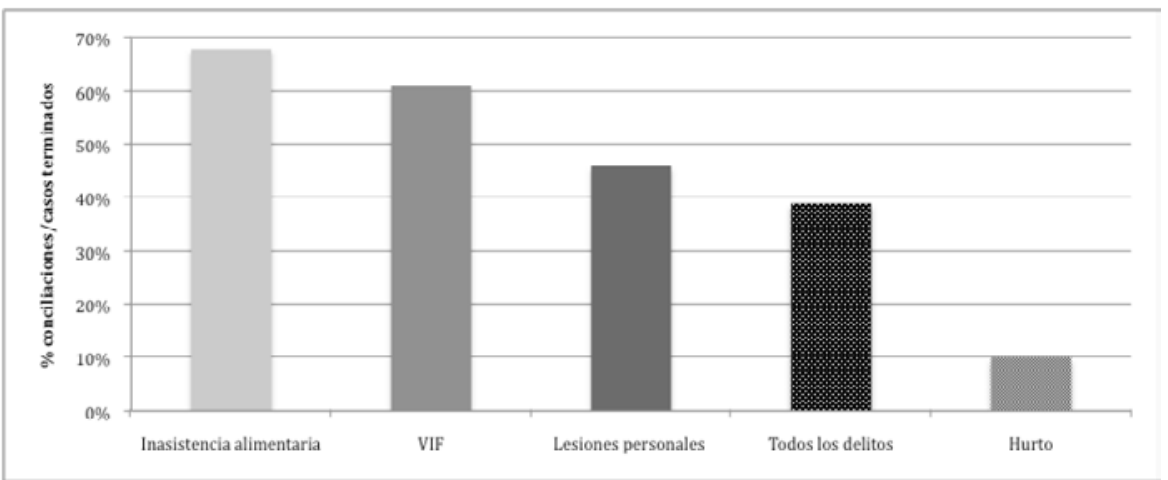

Fuente: Fiscalía General de la Nación

Como muestra el gráfico 2, entre 2005 y 2011, la conciliación era el principal mecanismo para tramitar casos de VIF. El $61 \%$ de los casos de VIF que terminaron en el sistema de justicia penal se resolvió mediante conciliación. El gráfico 2 ilustra que el porcentaje de casos de VIF terminados mediante conciliación era superior a la media de todos los delitos (39\%). Por el contrario, solo en un $0,9 \%$ de los casos reportados de VIF se profirió una sentencia condenatoria durante el mismo período.

Las académicas feministas y el movimiento de mujeres han formulado numerosas críticas frente a la aplicación de la conciliación en casos de VIF en Colombia: en primer lugar, el uso de la conciliación dejaba a las mujeres víctimas desprotegidas, ya que este

37 Fondo de Desarrollo de las Naciones Unidas para la Mujer, UNIFEM, Fondo de Población de las Naciones Unidas, UNFPA, Organización Internacional para las Migraciones, OIM, Programa Integral contra Violencias de Género, Estudio sobre tolerancia social e institucional a la violencia basada en género en Colombia, 191, 192 (Fondo de las Naciones Unidas y el Gobierno de España para el cumplimiento de los Objetivos de Desarrollo del Milenio, MDGF, Madrid, Bogotá, 2010). Disponible en: http://www.mdgfund.org/sites/default/files/GEN_ ESTUDIO_Colombia_Tolerancia $\% 20$ social $\% 20 \mathrm{e} \% 20$ institucional $\% 20 \mathrm{a} \% 201 \mathrm{a} \% 20$ violencia $\% 20 \mathrm{de} \% 20$ genero.pdf 
instrumento no tenía en cuenta cómo los mismos desequilibrios de poder que condujeron a la VIF podrían reproducirse en la conciliación. Por lo tanto, la conciliación abría espacios para nuevos abusos en un contexto de desigualdad de género ${ }^{38}$. En segundo lugar, la legislación y los funcionarios del Estado no garantizaban que las víctimas participaran voluntariamente en la audiencia de conciliación. El CPP de 2004 estableció una conciliación obligatoria como requisito de procedibilidad para estos casos. Además, algunas de las víctimas se sentían presionadas por el agresor o los funcionarios del Estado a aceptar la conciliación. Por ejemplo, el $37 \%$ de las mujeres víctimas entrevistadas por UNIFEM informaron que se sentían presionadas a conciliar ${ }^{39}$. En tercer lugar, la conciliación se aplicaba incluso en casos de violencia extremadamente grave ${ }^{40}$. En cuarto lugar, era muy probable que los agresores no cumplieran los acuerdos, debido a que no había mecanismos adecuados de monitoreo y sanciones por el incumplimiento ${ }^{41}$. De hecho, de los

38 Carolina Báez, Cecilia Barraza, Nathalia Buenahora, luz Piedad Caicedo \& Carolina LÓPEZ, La situación de las mujeres víctimas de violencias de género en el sistema penal acusatorio (Serie Acceso a la Justicia, 1, Corporación Humanas, Centro Regional de Derechos Humanos y Justicia de Género, Bogotá, 2008). Disponible en: http://www.bdigital.unal.edu.co/45466/. Julieta LemAitre-RIPOLL, Justicia injusta: una crítica feminista a la conciliación en violencia conyugal, 27 Revista de Derecho Privado, 73-98 (2002). Disponible en: https://derechoprivado. uniandes.edu.co/components/com_revista/archivos/derechoprivado/pri223.pdf

39 Fondo de Desarrollo de las Naciones Unidas para la Mujer, UNIFEM, Fondo de Población de las Naciones Unidas, UNFPA, Organización Internacional para las Migraciones, OIM, Programa Integral contra Violencias de Género, Estudio sobre tolerancia social e institucional a la violencia basada en género en Colombia, 146 (Fondo de las Naciones Unidas y el Gobierno de España para el cumplimiento de los Objetivos de Desarrollo del Milenio, MDGF, Madrid, Bogotá, 2010). Disponible en: http://www.mdgfund.org/sites/default/files/GEN_ ESTUDIO_Colombia_Tolerancia $\% 20$ social $\% 20 \mathrm{e} \% 20$ institucional $\% 20 \mathrm{a} \% 201 \mathrm{a} \% 20$ violencia $\% 20 \mathrm{de} \% 20$ genero.pdf

40 Julieta Lemaitre-Ripoll, Justicia injusta: una crítica feminista a la conciliación en violencia conyugal, 27 Revista de Derecho Privado, 73-98 (2002). Disponible en: https://derechoprivado. uniandes.edu.co/components/com_revista/archivos/derechoprivado/pri223.pdf

41 Julieta Lemaitre-Ripoll, Justicia injusta: una crítica feminista a la conciliación en violencia conyugal, 27 Revista de Derecho Privado, 73-98 (2002). Disponible en: https://derechoprivado. uniandes.edu.co/components/com_revista/archivos/derechoprivado/pri223.pdf. ANA RICO DE Alonso, María Cristina Hurtado \& Juan Carlos Alonso, Naturaleza del conflicto en el área de atención de familia (Consejo Superior de la Judicatura, Pontificia Universidad Javeriana, Bogotá, 1999). Fondo de Desarrollo de las Naciones Unidas para la Mujer, UNIFEM, Fondo de Población de las Naciones Unidas, UNFPA, Organización Internacional para las Migraciones, OIM, Programa Integral contra Violencias de Género, Estudio sobre tolerancia social e institucional a la violencia basada en género en Colombia, 146 (Fondo de las Naciones Unidas y el Gobierno de España para el cumplimiento de los Objetivos de Desarrollo del Milenio, MDGF, Madrid, Bogotá, 2010). Disponible en: http://www.mdgfund.org/sites/default/files/ GEN_ESTUDIO_Colombia_Tolerancia $\% 20$ social $\% 20 \mathrm{e} \% 20$ institucional $\% 20 \mathrm{a} \% 201 \mathrm{a} \% 20$ violencia $\% 20 \mathrm{de} \% 20$ genero.pdf 
fiscales que entrevisté, la mayoría dijo que no supervisaba el cumplimiento de los acuerdos, y que suponía que el infractor cumplió los términos del acuerdo cuando la víctima no regresaba a sus oficinas para quejarse de nuevo ${ }^{42}$.

Estas críticas de los defensores de los derechos de las mujeres nos llevan a un punto importante. Aunque el CPP de 2004 estableció la conciliación como mecanismo de justicia restaurativa, en la práctica, las audiencias de conciliación no cumplían los principios, valores y exigencias fundamentales de la justicia restaurativa. Las fallas principales son las siguientes:

1. Voluntariedad: el Manual sobre programas de justicia restaurativa $^{43}$ indica que la participación voluntaria de la víctima y el agresor es fundamental para el logro de los objetivos de la justicia restaurativa. El CPP de 2004 interfería con la voluntariedad, ya que estableció una audiencia de conciliación obligatoria para los casos de VIF. Además, algunas de las víctimas sentían presión para conciliar, debido a la presencia del agresor o al deseo de los funcionarios del Estado de lograr una terminación rápida de los casos.

2. La justicia restaurativa como un proceso largo: el Manual sobre programas de Justicia Restaurativa señala que en la justicia restaurativa es tan importante el proceso como el resultado, y el proceso para lograr un resultado restaurador verdadero puede necesitar mucho tiempo ${ }^{44}$. Por el contrario, en virtud del CPP de 2004, las autoridades implementaban la conciliación para llegar rápidamente a un acuerdo entre el agresor y la víctima, por lo general en una sola audiencia ${ }^{45}$.

3. Mecanismos de monitoreo: a pesar de que el Manual sobre programas de Justicia Restaurativa hace énfasis en la importancia

42 Entrevistas con fiscales del Centro de Atención contra la Violencia Intrafamiliar, CAVIF, 28, 29 y 30 de julio de 2014.

43 United Nations Office on Drug and Crime, UNODC, The Handbook on Restorative Justice Programmes, 8 (Criminal Justice Handbook Series, United Nations Office on Drug and Crime, UNODC, Vienna, New York, 2006). Disponible en: https://www.unodc.org/pdf/criminal_justice/06-56290_Ebook.pdf

44 United Nations Office on Drug and Crime, UNODC, The Handbook on Restorative Justice Programmes, 7 (Criminal Justice Handbook Series, United Nations Office on Drug and Crime, UNODC, Vienna, New York, 2006). Disponible en: https://www.unodc.org/pdf/criminal_justice/06-56290_Ebook.pdf

45 Entrevistas con fiscales del Centro de Atención contra la Violencia Intrafamiliar, CAVIF, 28, 29 y 30 de julio de 2014. 
de los mecanismos para supervisar el cumplimiento de las condiciones de los acuerdos entre las víctimas y los agresores ${ }^{46}$, el CPP de 2004 no estableció este tipo de mecanismos.

4. No dominación: John Braithwaite señala que uno de los valores de la justicia restaurativa es la no dominación. "Un programa no es restaurador si no es activo en la prevención de la dominación" ${ }^{97}$. Este autor sugiere que los procesos restaurativos deben incluir trabajo de preparación y la presencia de grupos de interés para restablecer el equilibrio en los casos en que ciertas partes están en una posición de poder más alta que las otras ${ }^{48}$. El CPP de 2004, sin embargo, concebía la conciliación como una sola audiencia, con exclusión de cualquier previsión para la preparación individual que pueda reducir las diferencias de poder. Esto es muy problemático en los casos de VIF, porque los desequilibrios de poder entre el agresor y la víctima son usuales.

Una de las razones por las que vemos brechas entre la teoría de justicia restaurativa y su práctica es que los funcionarios del Estado no han comprendido la idea de la justicia restaurativa. El CPP de 2004 no contiene una guía clara, ya que la formulación de objetivos y principios de la justicia restaurativa es ambigua e imprecisa. Además, el CPP de 2004 no establece requisitos particulares para los mecanismos de justicia restaurativa y el Fiscal General no ha publicado el manual sobre mediación y justicia restaurativa. El desarrollo de una formulación más precisa de los objetivos y los mecanismos de justicia restaurativa es crucial para lograr la implementación de verdaderos programas de justicia restaurativa en el país.

46 United Nations Office on Drug and Crime, UNODC, The Handbook on Restorative Justice Programmes, 77 (Criminal Justice Handbook Series, United Nations Office on Drug and Crime, UNODC, Vienna, New York, 2006). Disponible en: https://www.unodc.org/pdf/ criminal_justice/06-56290_Ebook.pdf

47 John Braithwaite, Principles of restorative justice, en Restorative Justice and Criminal Justice: Competing or Reconcilable Paradigms, 1-20, 9 (Andreas von Hirsch, Julian V. Roberts, ANthony E. Bottoms, Kent Roach, Mara Schiff, eds., Hart Publishing, Oxford, 2003). Disponible en: https://www.anu.edu.au/fellows/jbraithwaite/_documents/Articles/Principles $\% 20$ of $\% 20$ Restorative\%20Justice.pdf

48 John Braithwaite, Principles of restorative justice, en Restorative Justice and Criminal Justice: Competing or Reconcilable Paradigms, 1-20, 9 (Andreas von Hirsch, Julian V. Roberts, ANTHony E. Bottoms, Kent Roach, Mara Schiff, eds., Hart Publishing, Oxford, 2003). Disponible en: https://www.anu.edu.au/fellows/jbraithwaite/_documents/Articles/Principles $\% 20$ of $\% 20$ Restorative\%20Justice.pdf 
Una segunda razón es que los funcionarios del Estado pueden resistir la implementación de programas de justicia restaurativa reales puesto que estos pueden implicar mucho tiempo y esfuerzos. Los objetivos de la justicia restaurativa podrían prevenir la disposición excesivamente rápida de las causas y requerirían cambios en las rutinas de la conciliación profundamente arraigadas. En estas circunstancias, una aplicación activa de los programas de justicia restaurativa necesitaría políticas e incentivos institucionales que promuevan la implementación de procesos restaurativos ${ }^{49}$.

\section{LAS CONTRARREFORMAS PUNITIVAS AL CPP DE 2004 PARA COMBATIR LA VIOLENCIA INTRAFAMILIAR}

Teniendo en cuenta los defectos en la aplicación de la conciliación, los defensores de los derechos de las mujeres promovieron reformas legales para cambiar las respuestas estatales frente a la VIF. Algunos expertos, representantes de algunas ONG de mujeres y la Bancada de Mujeres en el Congreso han cuestionado el régimen del CPP de 2004 sobre la VIF con base en un enfoque punitivo de los derechos de las víctimas. Han promovido reformas legislativas para regular la VIF como un delito grave. En primer lugar, se han propuesto medidas de control de criminalidad para este tipo de violencia, como el aumento de penas, la ampliación de la detención preventiva y la prohibición de la detención domiciliaria ${ }^{50}$.

49 La Comisión Asesora de Política Criminal exhorta a la aplicación de programas de justicia restaurativa. La Comisión señala que la justicia restaurativa contribuye a armonizar los derechos de las víctimas y la idea de la ley penal como último recurso - ultima ratio-. La Comisión enfatiza que la justicia restaurativa ofrece una respuesta a los intereses y necesidades de las víctimas sin limitarse a estrategias punitivas. Comisión Asesora de Política Criminal, Informe final. Diagnóstico y propuesta de lineamientos de política criminal para el Estado colombiano, 69, 70 (Ministerio de Justicia y del Derecho, Agencia Presidencial de Cooperación Internacional de Colombia, APC Colombia, Unión Europea, Bogotá, 2012). Disponible en: https://www. minjusticia.gov.co/Portals/0/INFO\%20POLI\%20CRIMINAL_FINAL23NOV.pdf

50 Proyecto de Ley 23 de 2006, Cámara, por medio de la cual se reforman parcialmente las Leyes 906 de 2004 y 599 de 2000 y se adoptan medidas para la prevención y represión de la actividad delictiva de especial impacto para la convivencia y la seguridad ciudadana, Exposición de Motivos, 250 Gaceta del Congreso, 26 de julio de 2006. Disponible en: http://www.imprenta. gov.co/gacetap/gaceta.indice?v_num $=250 \& v \_a n o g=2006$. Proyecto de Ley 171 de 2006, Senado, por la cual se dictan normas para prevenir, erradicar y sancionar toda forma de violencia contra las mujeres, se reforman los Códigos Penal, de Procedimiento Penal, la Ley 294 de 1996 y se dictan otras disposiciones; acumulado con el Proyecto de Ley 98 de 2006, por la cual se reforma parcialmente la Ley 294 de 1996 y se dictan normas para la promoción 
Los defensores de los derechos de la mujer también han criticado las prácticas de persecución penal de la VIF en el marco del CPP de 2004. Han señalado que los fiscales no toman esta forma de violencia en serio y favorecen la conciliación, ya que creen que el maltrato es un delito menor y privado. Los críticos han argumentado que los fiscales a menudo no formulan imputaciones ni adelantan la persecución penal en los casos de VIF. En consecuencia, se han propuesto reformas a la ley para fomentar la persecución penal más activa, establecer la VIF como un delito que se persigue de oficio y restringir los mecanismos de justicia restaurativa ${ }^{51}$. Esta sección inicia con un análisis de las contrarreformas punitivas al CPP de 2004 para combatir la VIF. La segunda parte de esta sección analiza si los defensores de las mujeres han alcanzado sus objetivos en relación con la investigación, juzgamiento y sanción de la VIF.

\section{A. Aumento de las penas de prisión y establecimiento de la detención preventiva para los casos de VIF}

En 2007, la Ley de convivencia y seguridad ciudadana (Ley 1142) adoptó algunas de las medidas de control de criminalidad para la VIF propuestas por el movimiento de mujeres ${ }^{52}$. Durante los debates

integral de los derechos y de la igualdad de la mujer, 630 Gaceta del Congreso, 7 de diciembre de 2006. Disponible en: http://www.imprenta.gov.co/gacetap/gaceta.mostrar_documento ?p_tipo $=11 \&$ p_numero $=171 \&$ p_consec $=14170$

51 Proyecto de Ley 23 de 2006, Cámara, por medio de la cual se reforman parcialmente las Leyes 906 de 2004 y 599 de 2000 y se adoptan medidas para la prevención y represión de la actividad delictiva de especial impacto para la convivencia y la seguridad ciudadana, Exposición de Motivos, 250 Gaceta del Congreso, 26 de julio de 2006. Disponible en: http://www.imprenta. gov.co/gacetap/gaceta.indice?v_num $=250 \& v \_a n o g=2006$. CARolina BÁEZ, Cecilia BArRAZA, Nathalia Buenahora, Luz Piedad Caicedo \& Carolina López, La situación de las mujeres víctimas de violencias de género en el sistema penal acusatorio (Serie Acceso a la Justicia, 1, Corporación Humanas, Centro Regional de Derechos Humanos y Justicia de Género, Bogotá, 2008). Disponible en: http://www.bdigital.unal.edu.co/45466/

52 Con el fin de garantizar los derechos de las mujeres víctimas de VIF, los promotores de la Ley de violencia contra las mujeres propusieron medidas de control de criminalidad, como ampliar la procedencia de la detención preventiva, incentivar una persecución penal más activa y prohibir programas de justicia restaurativa (Proyecto de Ley 171 de 2006, Senado, por la cual se dictan normas para prevenir, erradicar y sancionar toda forma de violencia contra las mujeres, se reforman los Códigos Penal, de Procedimiento Penal, la Ley 294 de 1996 y se dictan otras disposiciones; acumulado con el Proyecto de Ley 98 de 2006, por la cual se reforma parcialmente la Ley 294 de 1996 y se dictan normas para la promoción integral de los derechos y de la igualdad de la mujer, 630 Gaceta del Congreso, 7 de diciembre de 2006. Disponible en: http://www.imprenta.gov.co/gacetap/gaceta.mostrar_documento?p_tipo=11\&p_numero $=171 \&$ p_consec $=14170)$. Al final, la ley sobre la violencia contra la mujer, aprobada en 2008, 
de la Ley 1142, la promoción de medidas más fuertes para enfrentar la VIF reforzó la agenda dominante de control de la criminalidad y seguridad pública. Los defensores de las mujeres trataron de promover la protección de los derechos de las mujeres víctimas reales o potenciales - con el fin de reducir la VCM y castigar a los agresores. El gobierno y algunos miembros del Congreso invocaron esencialmente los mismos símbolos — derechos de las víctimas-, pero su objetivo era mejorar la seguridad en las calles.

En los debates sobre la Ley de Convivencia y Seguridad Ciudadana (Ley 1142), la Bancada de Mujeres promovió medidas fuertes para enfrentar la VIF, como el aumento de la pena de prisión y la prohibición de la detención domiciliaria. El senador Roberto Gerlein (Partido Conservador) criticó estas medidas, con el argumento de que el alto número de casos de VIF podía contribuir al hacinamiento en el sistema penitenciario. Por el contrario, las senadoras Cecilia López, Martha Lucía Ramírez y Gloria Ramírez señalaron que el alto número de casos demostraba la gravedad de esta forma de violencia. En este contexto, era necesaria la regulación de estas conductas como delitos graves para erradicar la VCM. Por otra parte, López afirmó que esta decisión no sería una causa importante de problemas para el sistema penitenciario ${ }^{53}$.

Al final, los defensores de las mujeres lograron la promulgación de medidas de control de criminalidad para abordar la VIF. El artículo 33 de la Ley de convivencia y seguridad ciudadana (Ley 1142) aumentó las penas de prisión. La Ley 1142 aumentó casi al doble la pena máxima de prisión establecida por la Ley 890 de $2004^{54}$, y aumentó tres veces la pena mínima de prisión (gráfico 3). Este aumento significativo de la pena mínima de prisión por VIF buscaba permitir la imposición de la detención preventiva para los casos relacionados con este tipo de violencia. Así mismo, el artículo

excluyó todas estas medidas, debido a que fueron incorporadas por la Ley 1142 o de Convivencia y de la Seguridad Ciudadana en 2007. El Congreso discutió ambos proyectos de ley más o menos al mismo tiempo, pero la Ley 1142 de 2007 sobre seguridad ciudadana se promulgó antes, debido a que ese proyecto de ley era una de las prioridades del gobierno y el Congreso, por lo tanto, tenía un mensaje de urgencia.

53 Acta de la Plenaria 60, Senado, 22 de mayo de 2007, 331 Gaceta del Congreso, 19 de julio de 2007. Disponible en: http://www.imprenta.gov.co/gacetap/gaceta.mostrar_documento?p_ tipo $=02 \&$ p_numero $=60 \&$ p_consec $=15947$

54 Colombia, Ley 890 de 2004, por la cual se modifica y adiciona el Código Penal, 45.602 Diario Oficial, 7 de julio de 2004. Disponible en: http://www.secretariasenado.gov.co/senado/basedoc/ ley_0890_2004.html 
26 de la Ley 1142 prohibía la sustitución de la detención preventiva por detención domiciliaria en casos de VIF.

\section{Gráfico 3}

VIF: Aumento de las penas de prisión máximas y mínimas (en meses) (1996-2007)

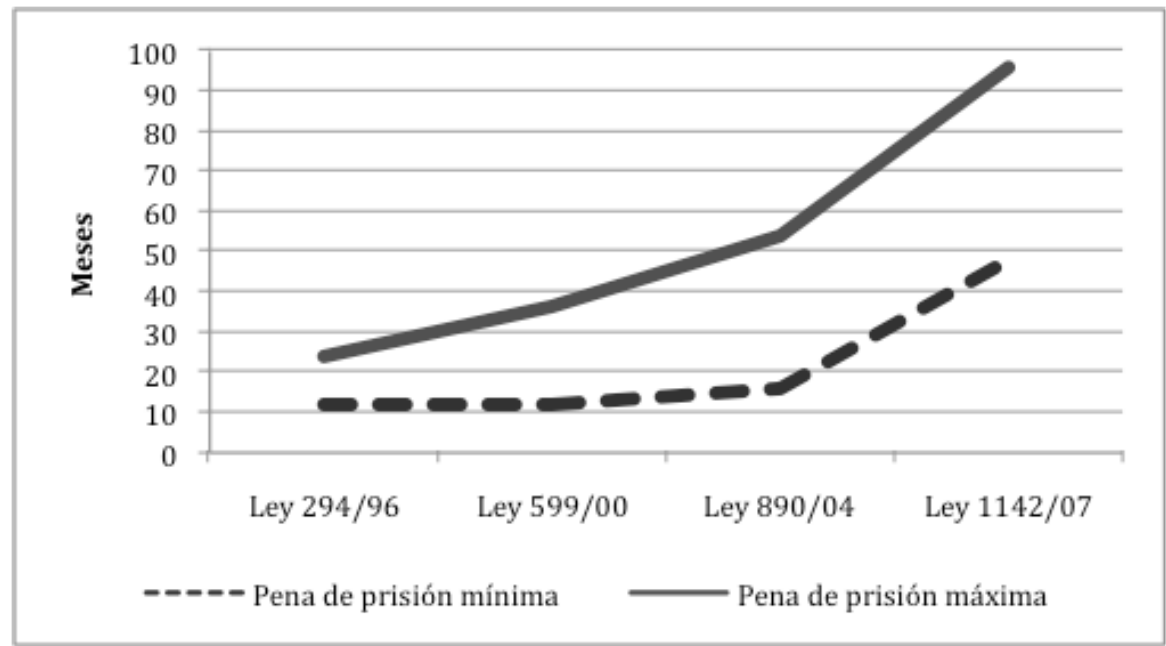

Fuente: elaboración propia

\section{B. La violencia intrafamiliar: alternando periodos de delito de oficio y delito querellable}

A partir de 2004, el Congreso ha promulgado varias reformas contradictorias sobre la VIF. Estas modificaciones legislativas muestran períodos alternantes de la VIF como delito investigable de oficio y como delito querellable (tabla 3). 


\section{Tabla 3}

\section{VIF: querellable vs. de oficio}

Querellable

De oficio

CPP, 2004 (Ley 906 de 2004)

Ley 1142 de 2007

Ley 1453 de 2011

Ley 1542 de 2012

Fuente: elaboración propia

En la "Ley de Convivencia y Seguridad Ciudadana" (Ley 1142 de 2007), el movimiento de mujeres tuvo éxito en la regulación de la VIF como un delito grave perseguible de oficio. La exposición de motivos de la "Ley de Convivencia y Seguridad Ciudadana" (Ley 1142 de 2007) argumentó que la VIF debe ser investigada de oficio. Señaló que el Estado debe proteger a las personas que se encuentren en circunstancias de debilidad manifiesta, y que esta forma de violencia es especialmente grave cuando las víctimas son vulnerables como los niños, los adolescentes y las mujeres. De acuerdo con la exposición de motivos de la Ley 1142, la persecución de oficio de la VIF y la prohibición de conciliación en estos casos favorecería el acceso a la justicia y enviaría un mensaje a la sociedad en torno a que este tipo de violencia es un grave abuso que no se tolera. ${ }^{55}$

En los debates en el Congreso sobre la "Ley de Convivencia y Seguridad Ciudadana" (Ley 1142 de 2007), se presentaron tres puntos de vista frente a las reformas propuestas. En primer lugar, algunos congresistas argumentaron que el CPP de 2004 debía mantener la VIF en la lista de delitos querellables, ya que este es un asunto privado. Dicho enfoque se basa en la distinción liberal entre las esferas pública y privada. En segundo lugar, la Bancada de Mujeres defendió la persecución de oficio de la VIF. Gina Parody y Martha Lucía Ramírez

55 Proyecto de Ley 23 de 2006, Cámara, por medio de la cual se reforman parcialmente las Leyes 906 de 2004 y 599 de 2000 y se adoptan medidas para la prevención y represión de la actividad delictiva de especial impacto para la convivencia y la seguridad ciudadana, Exposición de Motivos, 250 Gaceta del Congreso, 26 de julio de 2006. Disponible en: http://www.imprenta. gov.co/gacetap/gaceta.indice?v_num=250\&v_anog=2006 
argumentaron que el Estado debe ir al hogar y proteger a las mujeres debido a que la VCM es un asunto de interés público. En tercer lugar, algunos congresistas recomendaron una propuesta intermedia: la reforma eliminaría la VIF de la lista de delitos querellables, pero se permitiría conciliar y desistir de la querella. ${ }^{56}$

Al final, el artículo 4 de la Ley 1142 de 2007 excluyó la VIF de la lista de delitos querellables, así, los fiscales podrían investigar este delito sin una queja de la víctima. Sin embargo, el artículo 2 de la Ley 1142 estableció que sería posible aplicar el régimen y los efectos de los delitos querellables para asegurar la reparación de la víctima en los casos de VIF.

En 2011, la Ley de seguridad ciudadana (Ley 1453) ${ }^{57}$ estableció de nuevo la VIF como un delito querellable (artículo 108). El Congreso introdujo este cambio en el último debate sobre este proyecto de ley, sin ninguna discusión ${ }^{58}$. Los defensores de los derechos de las mujeres reclamaron que este cambio era inconstitucional debido a que no hubo un debate suficiente sobre el punto ${ }^{59}$.

En el mismo año, la Bancada de Mujeres promovió un nuevo proyecto de ley para establecer la VIF como un delito perseguible de oficio y para excluir la conciliación. La Bancada de Mujeres argumentó

56 Acta de la Plenaria 60, Senado, 22 de mayo de 2007, 331 Gaceta del Congreso, 19 de julio de 2007. Disponible en: http://www.imprenta.gov.co/gacetap/gaceta.mostrar_documento?p_ tipo $=02 \&$ p_numero $=60 \& p \_$consec $=15947$

57 Colombia, Ley 1453 de 2011, por medio de la cual se reforma el Código Penal, el Código de Procedimiento Penal, el Código de Infancia y Adolescencia, las reglas sobre extinción de dominio y se dictan otras disposiciones en materia de seguridad, 48.110 Diario Oficial, 24 de junio de 2011 Disponible en: http://www.secretariasenado.gov.co/senado/basedoc/ley_1453_2011. html

58 Ponencia para primer debate al Proyecto de Ley 164 de 2010, Senado, por medio de la cual se reforman el Código Penal, el Código de Procedimiento Penal, el Código de Infancia y Adolescencia, las reglas sobre Extinción de Dominio y se dictan otras disposiciones en materia de seguridad, 850 Gaceta del Congreso, 3 de noviembre de 2010. Disponible en: http://www. imprenta.gov.co/gacetap/gaceta.mostrar_documento?p_tipo $=12 \& p \_n u m e r o=164 \& p \_c o n s e c$ $=27508$. Texto aprobado en plenaria, Proyecto de Ley 164 de 2010, Senado, por medio de la cual se reforma el Código Penal, el Código de Procedimiento Penal, el Código de Infancia y Adolescencia, las reglas sobre extinción de dominio y se dictan otras disposiciones en materia de seguridad, 1117 Gaceta del Congreso, 22 de diciembre de 2010. Disponible en: http://servoaspr.imprenta.gov.co/gacetap/gaceta.nivel_3. Acta de Plenaria 28, Senado, 1 de diciembre de 2010, 70 Gaceta del Congreso, 7 de marzo de 2011. Disponible en: http://servoaspr. imprenta.gov.co/gacetap/gaceta.nivel_3. Acta de Plenaria 66, Cámara, 30 de mayo de 2011, 669 Gaceta del Congreso, 8 de sepriembre de 2011. Disponible en: http://servoaspr.imprenta. gov.co/gacetap/gaceta.nivel_3

59 Proyecto de Ley 164 de 2011, Senado, por la cual se reforma parcialmente la Ley 906 de 2004, Código de Procedimiento Penal, Exposición de Motivos, 853 Gaceta del Congreso, 11 de noviembre de 2011. Disponible en: http://servoaspr.imprenta.gov.co/gacetap/gaceta.nivel_3 
que la Ley de Seguridad Ciudadana (1453 de 2011) afectaba el derecho de las mujeres al acceso a la justicia, ya que el agresor podía tratar de controlar o intimidar a la víctima para evitar una investigación penal. Además, una mujer víctima podía llegar a un acuerdo desfavorable en una audiencia de conciliación por miedo, dependencia afectiva o financiera, o las condiciones desiguales entre ella y el agresor. La Bancada de Mujeres destacó que la Ley 1453 favoreció la impunidad y la discriminación contra las mujeres, y reforzó las representaciones tradicionales de la VIF como un delito menor ${ }^{60}$.

Los congresistas Miguel Gómez Martínez (Partido de la U), Carlos Germán Navas Talero (Polo Democrático Alternativo), Orlando Velandia (Partido Liberal), Alfredo Rafael Deluque (Partido de la U) y Óscar Fernando Bravo (Partido Conservador) se opusieron a este proyecto de ley por las siguientes razones: era necesario proporcionar mecanismos para mantener la unidad familiar. La legislación de justicia transicional -Acto legislativo 1 de 2012, Marco Jurídico para la $\mathrm{Paz}^{61}$ — buscaba la reconciliación con los integrantes de los grupos armados ilegales. En este contexto, se preguntaban por qué este proyecto de ley eliminaba medidas para favorecer la reconciliación y mantener unida la familia ${ }^{62}$.

Como respuesta a estas críticas, la Bancada de Mujeres y la Consejera Presidencial para la Equidad de la Mujer invocaron los derechos de la mujer y las obligaciones internacionales del Estado colombiano. Ellas enfatizaron que la VIF es una violación a los derechos humanos y el Estado debe actuar con la debida diligencia para prevenir, perseguir, sancionar y erradicar la VCM en el hogar. Recordaron que el Mecanismo de Seguimiento de la Convención de Belém do Pará ${ }^{63}$ (MESECVI) había recomendado al Estado

60 Proyecto de Ley 164 de 2011, Senado, por la cual se reforma parcialmente la Ley 906 de 2004, Código de Procedimiento Penal, Exposición de Motivos, 853 Gaceta del Congreso, 11 de noviembre de 2011. Disponible en: http://servoaspr.imprenta.gov.co/gacetap/gaceta.nivel_3

61 Colombia, Acto legislativo 1 de 2012, Marco Jurídico para la Paz, por medio del cual se establecen instrumentos jurídicos de justicia transicional en el marco del artículo 22 de la Constitución Política y se dictan otras disposiciones, 48.508 Diario Oficial, 31 de julio de 2012. Disponible en: http://www.secretariasenado.gov.co/senado/basedoc/acto_legislativo_01_2012. html

62 Ponencia para segundo debate al Proyecto de Ley 227 de 2012, Cámara; proyecto de ley 164 de 2011, Senado, por la cual se reforma el artículo 74 de la Ley 906 de 2004, Código de Procedimiento Penal, 305 Gaceta del Congreso, 4 de junio de 2012. Disponible en: http://servoaspr. imprenta.gov.co/gacetap/gaceta.nivel_3

63 Convención Interamericana para Prevenir, Sancionar y Erradicar la Violencia contra la Mujer, Convención de Belém do Pará, 9 de junio de 1994. Disponible en: http://www.oas.org/ 
colombiano garantizar el acceso a la justicia a las mujeres que sufren violencia, implementar programas estatales de asistencia a las mujeres víctimas de la violencia y eliminar la aplicación de métodos de conciliación para los casos de violencia de género. Las congresistas también afirmaron que el reconocimiento de la VIF como un delito que se persigue de oficio contribuye a proporcionar un recurso judicial adecuado para las mujeres víctimas. Ellas argumentaron que esta reforma de la ley enviaría el mensaje de que este tipo de violencia es un grave abuso reprochable desde el punto de vista penal y debe ser castigado ${ }^{64}$.

Los defensores de los derechos de las mujeres tuvieron éxito. La Ley 1542 de 2012 estableció la VIF como un delito investigable de oficio. Por lo tanto, los fiscales pueden adelantar la investigación penal sin tener en cuenta los deseos de la víctima, y no se exige la conciliación preprocesal obligatoria. El objetivo era garantizar que los casos de VIF fueran procesados y juzgados de manera más activa.

\section{El impacto de las contrarreformas punitivas al CPP de 2004}

Después de examinar las contrarreformas punitivas al CPP de 2004 en la sección anterior, la cuestión es si jlas reformas orientadas al control de la criminalidad han hecho que el sistema de justicia penal sea más punitivo para los casos de VIF? Este análisis de las contrarreformas punitivas al CPP de 2004 tiene algunas limitaciones. Es demasiado pronto para construir conclusiones definitivas sobre los efectos de estas reformas legales, en particular sobre la Ley 1542 de 2012, ya que es muy reciente y los datos disponibles solo representan unos pocos años de vigencia de la ley.

Desde la promulgación de la Ley 1142 de 2007, la población reclusa por VIF ha aumentado considerablemente (gráfico 4). Entre 2006 y 2015, este número aumentó más de veintidós veces, al pasar de 84 en 2006 a 1.869 en 2015. El número de presos condenados por VIF aumentó de 73 en 2006 a 1.032 en 2015, y el número de internos en

juridico/spanish/tratados/a-61.html, http://www.oas.org/es/mesecvi/default.asp

64 Ponencia para segundo debate al Proyecto de Ley 227 de 2012, Cámara; proyecto de ley 164 de 2011, Senado, por la cual se reforma el artículo 74 de la Ley 906 de 2004, Código de Procedimiento Penal, 305 Gaceta del Congreso, 4 de junio de 2012. Disponible en: http://servoaspr. imprenta.gov.co/gacetap/gaceta.nivel_3 
detención preventiva aumentó de 11 en 2006 a 837 en 2015. El número de presos en detención preventiva fue más alto que el número de internos condenados en 2012 y 2013. Estos datos muestran que el sistema de justicia penal se volvió más punitivo frente a la VIF después de las contrarreformas al CPP de 2004. Así las cosas, los defensores de las mujeres que promueven aproximaciones punitivas han tenido éxito en el aumento del uso de la prisión para este tipo de violencia.

\section{Gráfico 4}

\section{Población penitenciaria por el delito de VIF (1995-2015)}

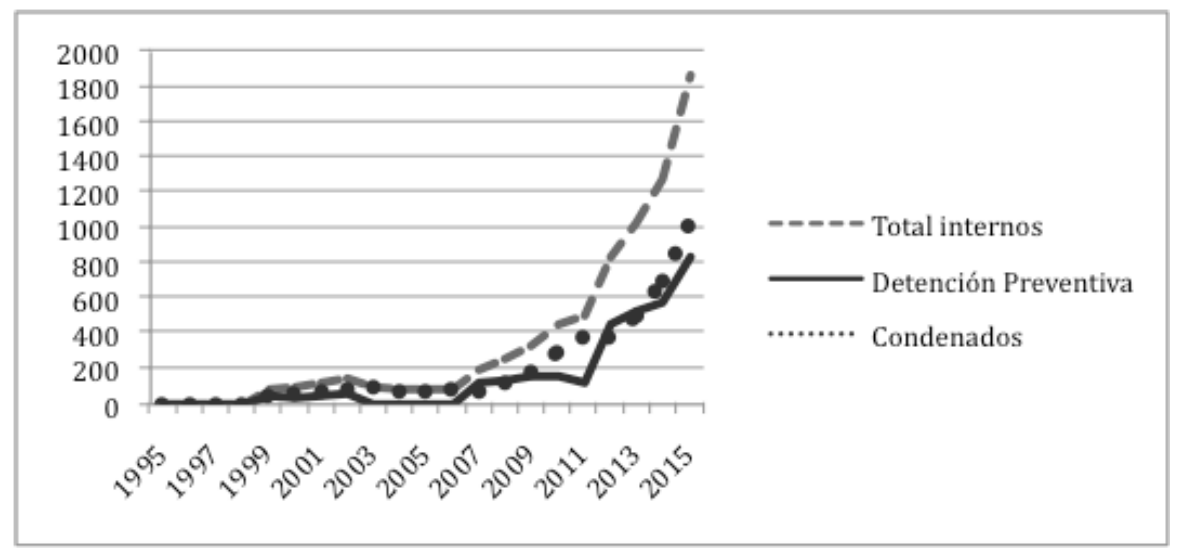

Fuente: Instituto Nacional Penitenciario y Carcelario, INPEC

Sin embargo, relativamente pocos agresores pasan tiempo en prisión en relación con la tasa de casos de VIF. El número de presos por VIF es pequeño, en comparación con los internos que ingresaron por otros delitos como lesiones personales y fabricación, tráfico, porte o tenencia de armas de fuego, accesorios, partes o municiones (en lo sucesivo porte de armas) ${ }^{65}$. El gráfico 5 compara la ratio de presos por casos de VIF reportados y por casos reportados de

65 Escogí estos dos delitos para hacer la comparación por las siguientes razones. El delito de lesiones personales puede ser considerado similar a la VIF. De hecho, algunos operadores de justicia usan el régimen de las lesiones personales para eludir las reglas de la VIF en los casos que califican como menos graves. El porte de armas y la VIF fueron parte de la agenda de control de criminalidad de 2007. La Ley 1142 aumentó las penas de prisión y expandió la detención preventiva para ambos delitos. Por lo tanto, esta comparación muestra los efectos diferenciales de la aplicación de las medidas de control de la criminalidad. 
lesiones personales ${ }^{66}$. De 2002 a 2014, la ratio media de presos por casos reportados de lesiones personales fue seis veces mayor que la ratio media de presos por casos de VIF. En 2006, la ratio entre los presos por VIF y los presos por lesiones personales empezó a disminuir; esta alcanzó su nivel más bajo en 2012 y 2013. En 2014, esta tendencia a la disminución cambió; la ratio entre los presos por VIF y los presos por lesiones personales aumentó 73\%. En términos generales, estos datos sugieren que el uso de cárcel por VIF está alcanzando los niveles de encarcelamiento por lesiones personales. Sin embargo, en 2014, la ratio por lesiones personales $(0,055)$ fue más de tres veces la ratio por VIF $(0,017)$. Estos datos indican que ir a prisión por lesiones personales es más probable que por VIF.

\section{Gráfico 5}

Ratio de internos por casos reportados:

VIF y lesiones personales (2002-2014)

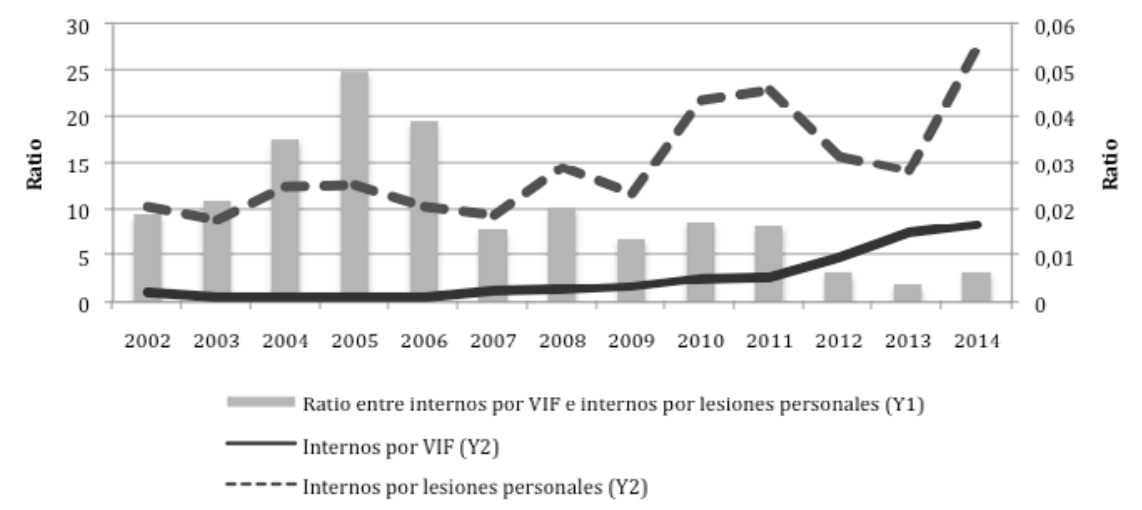

Fuente: Instituto Nacional Penitenciario y Carcelario, INPEC; Policía Nacional, Revista Criminalidad; Instituto Nacional de Medicina Legal y Ciencias Forenses (INML), Forensis

Así mismo, el número de presos por VIF es relativamente pequeño en comparación con el número de personas privadas de la libertad por porte de armas ${ }^{67}$. El porte de armas representa una fracción sig-

66 La medida es: Ratio de presos por casos reportados de un delito en particular = número de presos por ese delito dividido por los casos reportados de ese delito.

67 Esta sección analiza el tipo penal fabricación, tráfico, porte o tenencia de armas de fuego, accesorios, partes o municiones. Este delito se refiere a armas de defensa personal; por ello, 
nificativa de la población reclusa en Colombia. El gráfico 6 muestra la ratio de presos por casos reportados de VIF y la ratio de presos por casos registrados de porte de armas. Tanto el número de presos por porte de armas como el número de presos por VIF empezaron a aumentar en 2007, con la Ley de 1142. Sin embargo, la ratio de presos por porte de armas fue 39 veces la ratio de presos por VIF, entre 2007 y 2009. En 2010, la población reclusa por porte de armas aumentó significativamente, mucho más que la población de presos por VIF. Entre 2010 y 2014, la media de la ratio de presos por porte de armas fue 109 veces la media de la ratio de presos por VIF.

\section{Gráfico 6}

Ratio número de internos por casos reportados: VIF y porte de armas (2002-2014)

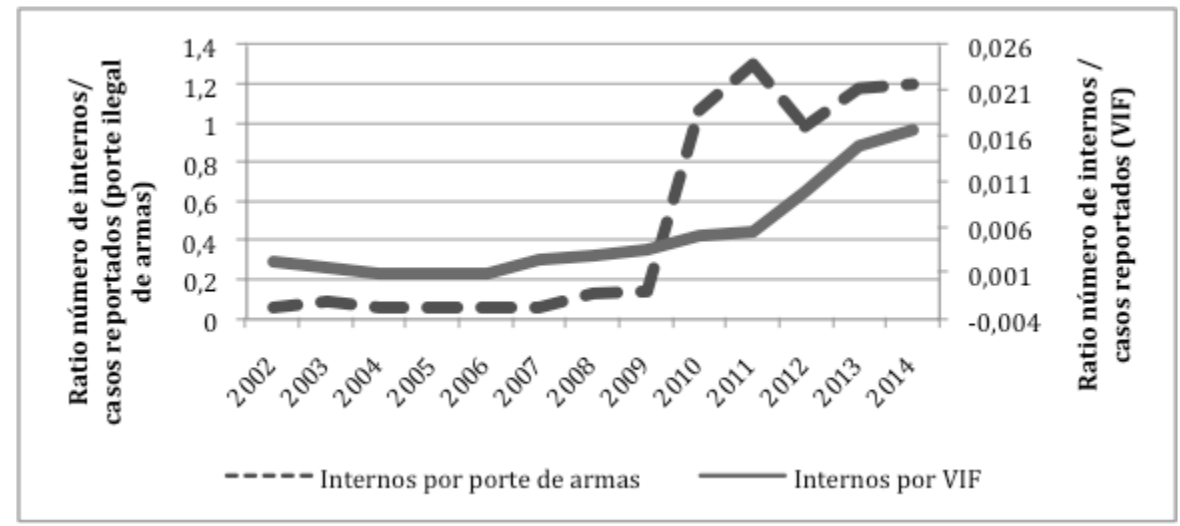

Fuente: Instituto Nacional Penitenciario y Carcelario, INPEC; Policía Nacional, Revista Criminalidad; Instituto Nacional de Medicina Legal y Ciencias Forenses (INML), Forensis

La agenda de control de criminalidad de la Ley 1142 de 2007 incluyó la VIF y el porte de armas. Esta ley aumentó las penas de prisión y permitió la detención preventiva para estos delitos. En ese momento, las penas para estos dos crímenes eran las mismas. En 2011, la Ley 1453 volvió a aumentar las penas de prisión por porte de armas (gráfico 7). Al final, las reformas punitivas y de control

los datos examinados solo incluyen el porte ilegal de armas de defensa personal. Mi análisis no incluye información relativa al tipo penal fabricación, tráfico y porte de armas, municiones de uso restringido, de uso privativo de las Fuerzas Armadas o explosivos. 
de criminalidad tuvieron un mayor impacto en el aumento del uso de la prisión en casos de porte de armas que en casos de VIF.

\section{Gráfico 7}

Penas de prisión para porte ilegal de armas

y VIF Penas mínimas, penas máximas

\section{Penas mínimas}

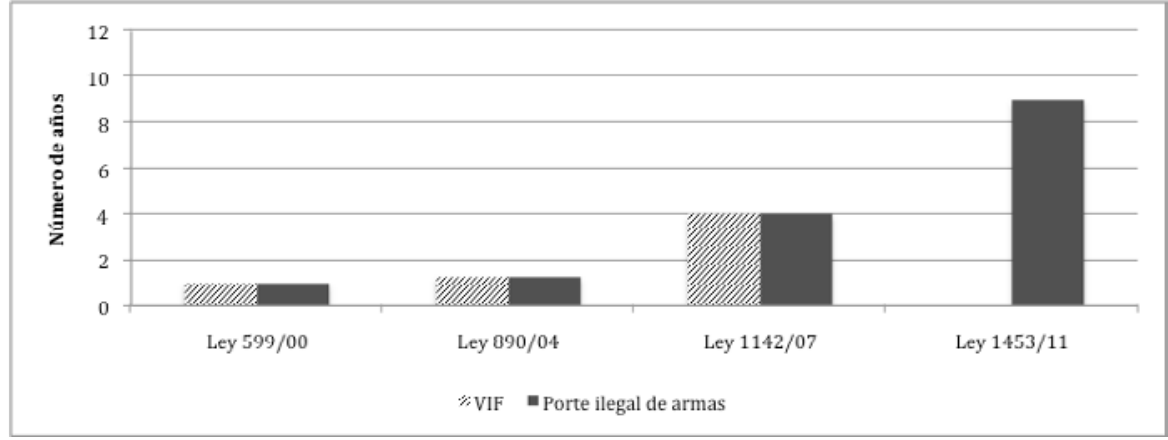

\section{Penas máximas}

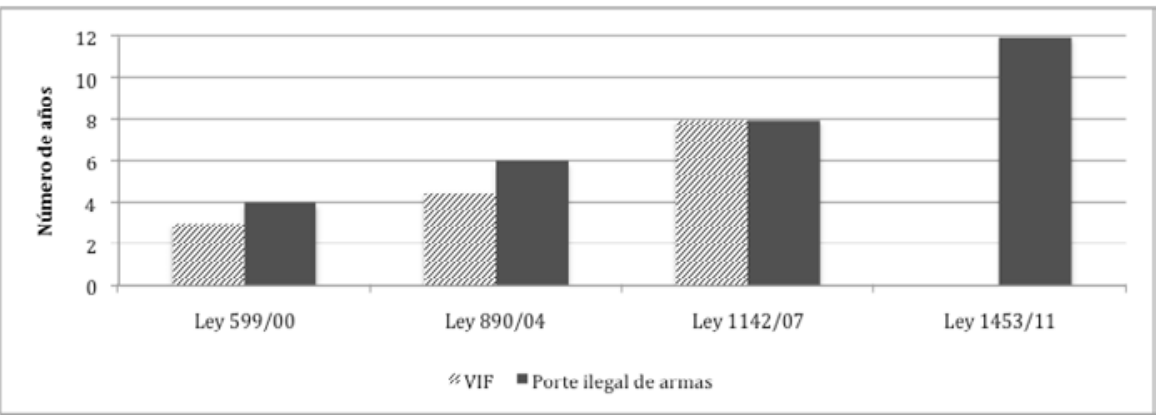

Si la VIF y el porte de armas estaban en la agenda de control de criminalidad en 2007, ¿por qué el sistema de justicia penal llegó a ser más punitivo para el porte de armas? Varios factores han contribuido al aumento dramático de la población reclusa por porte de armas. Un primer factor es un compromiso político fuerte. Desde 2009, el gobierno nacional y los gobiernos locales han puesto en marcha iniciativas para el control del porte de armas, con el argumento de que este delito amenaza la seguridad ciudadana debido a que está 
relacionado con crímenes violentos ${ }^{68}$. Un segundo factor es que las autoridades de policía están comprometidas con la implementación de medidas de control de la criminalidad frente a este delito. Por ejemplo, las directrices para la seguridad ciudadana de la Policía Nacional fomentan la persecución del porte y tráfico de armas ${ }^{69}$. Un tercer factor es la presión de los medios de comunicación y el público en general sobre los jueces de control de garantías para que decreten medidas de detención preventiva en casos de porte de armas. Un cuarto factor es la ampliación del tipo penal de porte de armas para incluir la posesión de piezas o accesorios (Ley 1453 de 2011). Un último factor es que los delitos de porte o posesión son fáciles de procesar y castigar porque se prueban a sí mismos.

Por el contrario, algunos funcionarios del Estado se han resistido a aplicar las medidas fuertes de control de criminalidad en casos de VIF por dos razones ${ }^{70}$. En primer lugar, todavía creen que la VIF es un delito menor ${ }^{71}$. Tradicionalmente, la violencia dentro de la familia ha sido tratada como una ofensa menos grave que los delitos cometidos en el ámbito público ${ }^{72}$. En segundo lugar, las instituciones del

68 El control de armas ha sido una estrategia para reducir los crímenes violentos. KATHERINE AGUIRRE \& JoRge A. RESTREPO, El control de armas como estrategia de reducción de la violencia en Colombia: pertinencia, estado y desafíos, 52 Revista Criminalidad, 1, 265-284 (2007). Disponible en: http://www.policia.gov.co/imagenes_ponal/dijin/revista_criminalidad/vol52_1/07ElControl. pdf. El control del porte de armas fue central en la Política de Seguridad Democrática del presidente Álvaro Uribe para garantizar la seguridad pública. Catalina Bello-Montes, El control de las armas ligeras: retos y desafíos para el nuevo milenio, 47 Revista Criminalidad, Capítulo VI, Fortalecimiento y Logros de la Seguridad Democrática, 6-16 (2005). Disponible en: http://www.policia.gov.co/imagenes_ponal/dijin/revista_criminalidad/vol47/14.pdf, http:// www.policia.gov.co/portal/page/portal/HOME/publicaciones/revista_criminalidad/47

69 La Policía Nacional ha otorgado incentivos para la detención de quienes cometan el delito porte de armas. Policía Nacional de Colombia, Lineamientos generales de política para la Policía Nacional de Colombia (Policía Nacional de Colombia, Bogotá, 2007). Disponible en: http://pdba.georgetown.edu/Security/citizensecurity/Colombia/politicas/lineamientospolicia. pdf. Policía Nacional de Colombia, Lineamientos generales de política para la Policía Nacional de Colombia (Policía Nacional de Colombia, Bogotá, 2010). Disponible en: http://www. policia.gov.co/portal/page/portal/HOME/Lineamientos/TOMO $\% 200$-LINEAMIENTOS $\% 20$ GENERALES\%20DE\%20POLITICA\%20PARA\%20LA\%20PONAL.pdf

70 Sally Merry señala que los agentes de policía y los tribunales subvierten las leyes que criminalizan la violencia doméstica o VIF en muchas partes del mundo. Sally Engle Merry, Gender Violence: A Cultural Perspective, 51 (Wiley-Blackwell, Hoboken, New Jersey, 2009).

71 Entrevista con una abogada de la Secretaría Distrital de la Mujer de Bogotá, 28 de julio de 2014. Entrevista con una abogada de la ONG Humanas, 6 de agosto de 2014.

72 Martha Fineman \& Roxanne Mykitiuk, eds., The Public Nature of Private Violence: The Discovery of Domestic Abuse (Routledge, New York, 1994). Julieta Lemaitre-Ripoll, Justicia injusta: una crítica feminista a la conciliación en violencia conyugal, 27 Revista de Derecho Privado, 73-98 (2002). Disponible en: https://derechoprivado.uniandes.edu.co/components/ com_revista/archivos/derechoprivado/pri223.pdf. Sally Engle Merry, Gender Violence: A Cultural Perspective (Wiley-Blackwell, Hoboken, New Jersey, 2009). 
Estado que se ocupan de la VIF están sobrecargadas y carecen de personal suficiente; por lo tanto, muchos funcionarios prefieren una disposición eficiente y rápida de los casos en lugar del castigo penal ${ }^{73}$.

Debido a que muchos funcionarios del Estado no están de acuerdo con los supuestos y objetivos del movimiento de mujeres, no están comprometidos con la aplicación de medidas fuertes de control de criminalidad para manejar los casos de VIF. Así las cosas, hay patrones de incumplimiento de estas normas por parte de autoridades estatales, que incluyen infringir sus obligaciones, restringir la definición de la VIF y aplicar a los casos de VIF disposiciones legales diseñadas para otros delitos menos fuertes que las establecidas para la VIF.

\section{Gráfico 8}

\section{Casos enviados a la Fiscalía General de la Nación por los comisarios de familia (2010)}

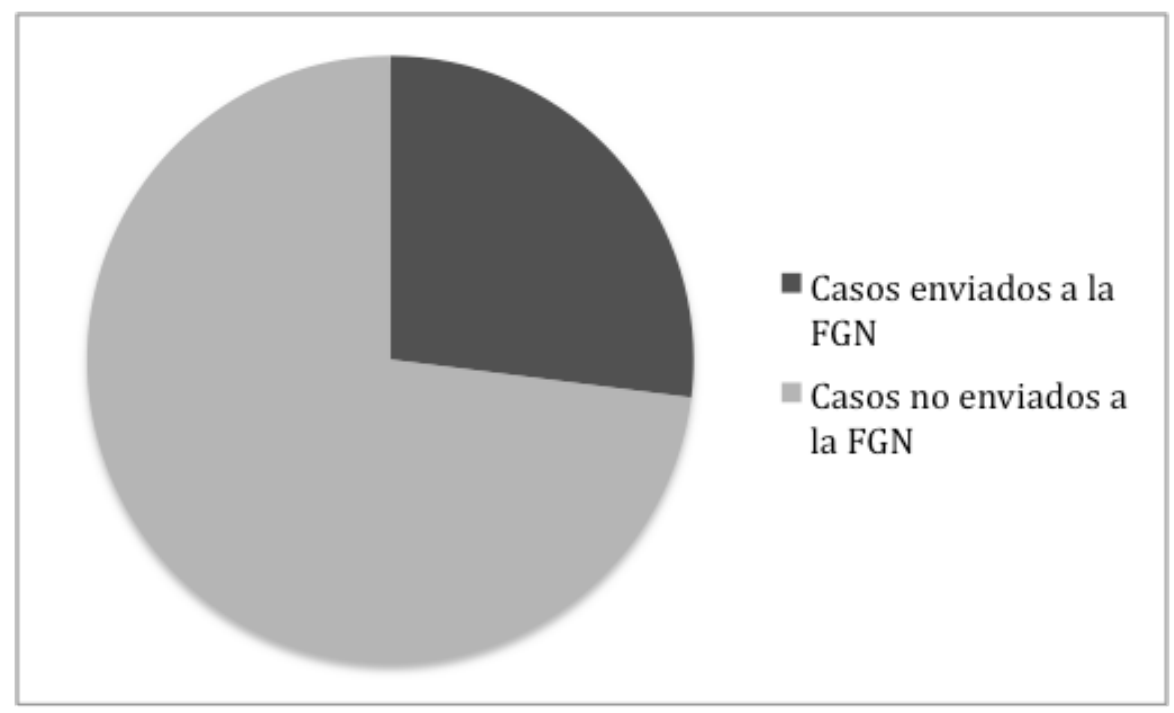

Fuente: Procuraduría General de la Nación ${ }^{74}$

73 Entrevistas a una abogada de la Secretaría Distrital de la Mujer de Bogotá y con fiscales del Centro de Atención contra la Violencia Intrafamiliar, CAVIF, 28, 29 y 30 de julio de 2014. Entrevista con una abogada de la ONG Humanas, 6 de agosto de 2014.

74 Procuraduría General de la Nación, Comisarías de Familia. Línea de Base Nacional, 6, 7 Procurando la Equidad, números especiales $(2011,2012)$. Primera parte disponible en: http://www. procuraduria.gov.co/portal/media/file/PROCURANDO7_WEB $\% 20$ final $\% 20$ nov\%2023.pdf 
Algunos funcionarios estatales incumplen sus deberes establecidos por las reformas legales. Por ejemplo, los comisarios de familia no envían todos los casos de VIF a la Fiscalía General de la Nación, a pesar de que la Ley 1257 de $2008^{75}$ les impone la obligación de reportar todos los incidentes de VIF. En 2010, los comisarios de familia solo enviaron el $27 \%$ de los casos (gráfico 8). Si los comisarios de familia hubieran reportado todos los casos que recibieron (108.778), ese año el número de ingresos por VIF en la Fiscalía General de la Nación habría sido más del doble.

Adicionalmente, algunos funcionarios estatales restringen la definición de la VIF y "despenalizan", en la práctica, los abusos emocionales y psicológicos. Algunos funcionarios solo se toman en serio los casos en los que el agresor ha infligido lesiones físicas graves. En las prácticas institucionales, la violencia física se convierte en un requisito implícito para investigar, juzgar y sancionar la $\mathrm{VIF}^{76}$. A pesar de que la Ley sobre la VCM amplió el significado de la VIF, incluyendo las dimensiones emocionales y psicológicas, el sistema de justicia penal no tiene en cuenta estas dimensiones de la violencia. Por ejemplo, el Instituto Nacional de Medicina Legal no incluye exámenes forenses de violencia psicológica o emocional en los informes estadísticos. Además, los fiscales entrevistados reconocían que la violencia emocional es grave, pero justificaban la ausencia de persecuciones penales de este tipo de violencia con el argumento de que las probabilidades de conseguir una condena son muy bajas ${ }^{77}$.

Del mismo modo, algunos funcionarios estatales deciden no aplicar el régimen restrictivo y severo de la VIF a aquellas situaciones catalogadas como menos peligrosas. Estos funcionarios consideran que la aplicación mecánica de reglas severas puede implicar injusticias en algunos casos. Por ejemplo, algunos incidentes de violencia dentro de la familia se tipifican como lesiones

75 Colombia, Ley 1257 de 2008, por la cual se dictan normas de sensibilización, prevención y sanción de formas de violencia y discriminación contra las mujeres, se reforman los Códigos Penal, de Procedimiento Penal, la Ley 294 de 1996 y se dictan otras disposiciones, 47.193 Diario Oficial, 4 de diciembre de 2008. Disponible en: http://www.secretariasenado.gov.co/ senado/basedoc/ley_1257_2008.html

76 Entrevista con una abogada de la Secretaría Distrital de la Mujer de Bogotá, 28 de julio de 2014.

77 Entrevistas a la directora del Centro de Atención contra la Violencia Intrafamiliar, CAVIF y con fiscales del CAVIF, 28, 29 y 30 de julio de 2014. 
personales para eludir las reglas aplicables a la VIF y poder llevar a cabo audiencias de conciliación ${ }^{78}$.

Parece que las reformas legales punitivas para combatir la violencia dentro de la familia han tenido consecuencias no deseadas para las víctimas. De acuerdo con los fiscales y abogados de las víctimas que entrevisté ${ }^{79}$, la idea de punitividad en el régimen de la VIF se ha convertido en un desincentivo para la participación de la víctima en el proceso penal. El número de casos reportados a la Fiscalía General de la Nación disminuyó 6\% entre 2011 y 2013. Este dato indica que el enfoque punitivo puede desalentar la denuncia y la cooperación de la víctima, lo cual puede afectar la protección de la víctima y la probabilidad de una condena.

De acuerdo con los fiscales entrevistados, muchas víctimas se niegan a cooperar o proporcionar información a los funcionarios de la fiscalía cuando se dan cuenta de que la consecuencia del proceso será prisión. Los fiscales y los defensores de las mujeres entrevis$\operatorname{tados}^{80}$ señalaron que muchas mujeres víctimas quieren que sus agresores detengan el abuso, pero no quieren enviarlos a la cárcel.

Una comparación de los datos sobre VIF de la Policía Nacional y del Instituto Nacional de Medicina Legal muestra el efecto de las medidas punitivas en la cooperación de la víctima. Mientras que el número de casos de VIF reportados a la Policía Nacional aumentó de forma constante desde 1999 hasta 2014 (gráfico 9), el número de casos examinados por el Instituto Nacional de Medicina Legal (INML) se redujo de 93.843 en 2009 a 68.230 en 2013; en otras palabras, el número de víctimas examinadas por el INML disminuyó

78 Una abogada de la Secretaría Distrital de la Mujer de Bogotá entrevistada señaló que la aplicación de otros delitos era una práctica frecuente de los fiscales y los comisarios de familia para evitar la implementación de las normas relativas a la VIF (entrevista, 28 de julio de 2014). Observé una audiencia de conciliación ante un comisario de familia en la que identificaron los hechos como lesiones personales para permitir la conciliación, a pesar de que, de acuerdo con el Código Penal, este incidente constituía VIF. El padre le dio una nalgada a su hijo de 6 años como una forma de disciplina y le dejó la mano marcada. El comisario de familia explicó que iba a aplicar las disposiciones acerca de las lesiones personales porque pensó que este acto no era lo suficientemente grave como para enviar el padre a la cárcel (audiencia de conciliación en Ciudad Bolívar, Bogotá, marzo de 2010).

79 Entrevistas a la directora del Centro de Atención contra la Violencia Intrafamiliar, CAVIF, con fiscales del CAVIF y a una abogada de la Secretaría Distrital de la Mujer de Bogotá, 28, 29 y 30 de julio de 2014. Entrevista con una abogada de la ONG Humanas, 6 de agosto de 2014.

80 Entrevistas a la directora del Centro de Atención contra la Violencia Intrafamiliar, CAVIF, con fiscales del CAVIF y a una abogada de la Secretaría Distrital de la Mujer de Bogotá, 28, 29 y 30 de julio de 2014. Entrevista con una abogada de la ONG Humanas, 6 de agosto de 2014. 
en un 27\% entre 2009 y 2013 (gráfico 10). En 2014, el número de casos examinados por el INML aumentó en 11\%, de 68.230 en 2013 a 75.939 en 2014. Sin embargo, este último seguía estando $19 \%$ por debajo de su pico en 2009. Una posible explicación para las diferencias en la tendencia del número de víctimas registradas en estas dos instituciones es que las víctimas denuncian el caso, y cuando los funcionarios les explican el régimen estricto y sus consecuencias, las víctimas deciden no acudir al INML para el examen forense ${ }^{81}$. Los fiscales entrevistados ${ }^{82}$ resaltaron que el enjuiciamiento de estos delitos se basa principalmente en el testimonio y el examen forense de la víctima. Observaron que la condena sin la cooperación víctima es casi imposible, ya que los agresores suelen cometer estos delitos en espacios privados sin testigos. En consecuencia, el enfoque punitivo a la violencia intrafimiliar podría estar siendo contraproducente para el procesamiento de este tipo de violencia.

\section{Gráfico 9}

\section{Casos de VIF reportados a la Policía Nacional (1999-2014)}

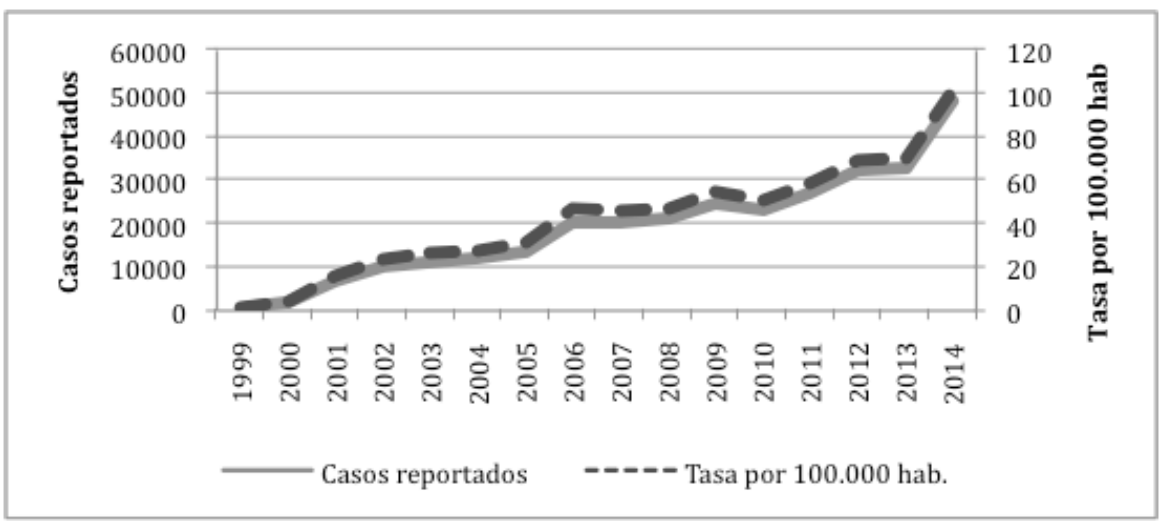

Fuente: Policía Nacional, Revista Criminalidad

81 Un fiscal del CAVIF señaló que después de que él describe la legislación a las víctimas, algunas no regresan a su oficina, y él tiene que archivar el caso por falta de pruebas (entrevista con un fiscal del CAVIF, 28 de julio de 2014).

82 Entrevistas a la directora del Centro de Atención contra la Violencia Intrafamiliar, CAVIF y con fiscales del CAVIF, 28, 29 y 30 de julio de 2014. 


\section{Gráfico 10}

\section{Casos de VIF examinados por el INML (2000-2014)}

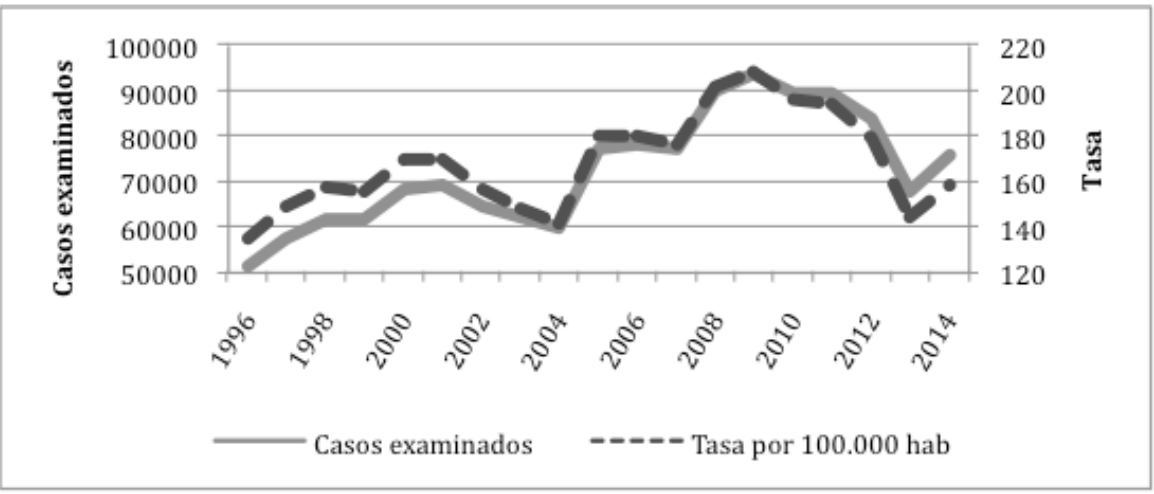

Fuente: Instituto Nacional de Medicina Legal y Ciencias Forenses, Forensis

A pesar de estos problemas, algunos fiscales con un enfoque feminista y algunos defensores de mujeres ${ }^{83}$ consideran que las medidas de control de criminalidad son un avance para garantizar la protección de los derechos de la mujer y la investigación, persecución y sanción de la VCM. Señalan que es necesario implementar medidas de asistencia psicosocial y jurídica adecuadas para empoderar a las víctimas para participar y, por lo tanto, para lograr los objetivos de las reformas legales punitivas promovidas por el movimiento de mujeres.

Aunque estas conclusiones no son definitivas porque algunas de las reformas legales punitivas son muy recientes, los datos analizados sugieren que las reformas de las leyes punitivas han tenido resultados mixtos. El aumento de las condenas por VIF es bastante bajo en relación con otros delitos, y el enfoque punitivo parece haber tenido el resultado no deseado de alejar a algunas de las mujeres víctimas del proceso penal.

La alianza entre el movimiento de mujeres y los actores que promovían las agendas de control de la criminalidad y seguridad ciudadana en las contrarreformas al CPP de 2004 ha tenido efectos asimétricos, a favor de la seguridad ciudadana. Algunos funciona-

83 Entrevistas a la directora del Centro de Atención contra la Violencia Intrafamiliar, CAVIF, con fiscales del CAVIF y a una abogada de la Secretaría Distrital de la Mujer de Bogotá, 28, 29 y 30 de julio de 2014. Entrevista con una abogada de la ONG Humanas, 6 de agosto de 2014. 
rios estatales se han resistido a la aplicación de medidas de control de la criminalidad en los casos de VIF, ya que consideran que la VIF es un delito menor en relación con delitos como el porte de armas. Por lo tanto, el objetivo de la seguridad ciudadana puede haber opacado esfuerzos para enviar mensajes sobre la igualdad de género y la intolerancia de la VCM. En este contexto, los defensores de las mujeres deben ser cuidadosos con la promoción de estrategias punitivas para enfrentar la VIF.

\section{VIOLENCIA INTRAFAMILIAR: ENTRE UN ENFOQUE PUNITIVO Y UN ENFOGUE DE JUSTICIA RESTAURATIVA}

Las reformas al CPP de 2004 sobre el método de persecución de la VIF reproducen la tensión entre un enfoque punitivo y un enfoque de justicia restaurativa. Los defensores de las mujeres han expresado su preocupación acerca de la implementación de la justicia restaurativa en el contexto de esta forma de violencia, y por lo tanto, han promovido el castigo como una respuesta más adecuada a la VCM.

Muchas feministas cuestionan el uso de la justicia restaurativa para atender la VIF, ya que estos mecanismos pueden revictimizar a las mujeres víctimas, reforzar su subordinación, excusar y trivializar la violencia masculina, presionar a las mujeres víctimas, reprivatizar la VIF masculina y poner a las víctimas en riesgo de abuso continuado ${ }^{84}$. En el mismo sentido, la Comisión Interamericana de Derechos Humanos, CIDH, sostiene que los mecanismos alternativos de solución de conflictos (MASC), como la conciliación y la mediación, son obstáculos para el acceso a la justicia de las mujeres $^{85}$. Del mismo modo, el Mecanismo de Seguimiento de la

84 Carolina Báez, Cecilia Barraza, Nathalia Buenahora, luz Piedad Caicedo \& Carolina LóPEZ, La situación de las mujeres víctimas de violencias de género en el sistema penal acusatorio, 32, 33 (Serie Acceso a la Justicia, 1, Corporación Humanas, Centro Regional de Derechos Humanos y Justicia de Género, Bogotá, 2008). Disponible en: http://www.bdigital.unal.edu. co/45466/. Jennifer Gerarda Brown, The Use of Mediation to Resolve Criminal Cases: A Procedural Critique, 43 Emory Law Journal, 1247-1309 (1994). JANA B. Singer, The Privatization of Family Law, 5 Wisconsin Law Review, 1443-1567 (1992). Julie STubBs, Beyond Apology? Domestic Violence and Critical Questions for Restorative Justice, 7 Criminology and Criminal Justice, 2, 169-187 (2007). Julie Stubbs, Domestic Violence and Women's Safety: Feminist Challenges to Restorative Justice, en Restorative Justice and Family Violence, $42-61$ (HeAther STRANG \& John Braithwaite, eds., 2002).

85 "Entre otras deficiencias y peligros, la CIDH ha expresado su preocupación ante el hecho de 
Convención de Belém do Pará (MESECVI) recomienda evitar la aplicación de MASC en casos de violencia de género ${ }^{86}$.

De acuerdo con esta lógica, muchas organizaciones de mujeres en Colombia se oponen a la aplicación de MASC y a la justicia restaurativa para tratar los casos de VIF. En su lugar, muchos defensores de las mujeres promueven estrategias punitivas y argumentan que una política de persecución penal proactiva es la respuesta apropiada a la VIF, ya que protege a las víctimas y reconoce que la VCM es un problema público que afecta a la sociedad y constituye una violación a los derechos humanos ${ }^{87}$. Las políticas de persecución

que una diversidad de órganos judiciales promueven principalmente el uso de la conciliación durante el proceso de investigación como método para resolver delitos de violencia contra las mujeres, sobre todo la intrafamiliar. Es de reconocimiento internacional que la conciliación en casos de violencia intrafamiliar no es recomendable como método para resolver estos delitos. Un gran número de expertas y organismos internacionales han identificado los peligros del uso de la conciliación como método para resolver casos de violencia, sobre todo la violencia doméstica. Han manifestado que al hacer este delito conciliable, el delito se vuelve sujeto de negociación y transacción entre la víctima y el victimario. La conciliación asume que las partes involucradas se encuentran en igualdad de condiciones de negociación, lo cual generalmente no es el caso en el ámbito de la violencia intrafamiliar. En varios países ha quedado claro que los acuerdos realizados en el marco de mediación aumentan el riesgo físico y emocional de las mujeres por la desigualdad en las relaciones de poder entre la víctima y el agresor. Los acuerdos generalmente no son cumplidos por el agresor y estos no abordan las causas y consecuencias de la violencia en sí”. Organization of American States, OAS, Inter-American Commission on Human Rights, IACHR (Organización de los Estados Americanos, OEA, Comisión Interamericana de Derechos Humanos, CIDH), Access to Justice for Women Victims of Violence in the Americas, OEA/Ser.L/V/II, Doc. 68, 20 January 2007, par. 161 (Organization of American States, OAS, Inter-American Commission on Human Rights, CIDH, Washington, 2007). Disponible en: https://www.cidh.oas.org/women/Access07/Report $\% 20$ Access $\% 20$ to\%20Justice\%20Report\%20English\%20020507.pdf, http://www.cidh.oas.org/pdf\%20files/ Informe $\% 20$ Acceso $\% 20 \mathrm{a} \% 201 \mathrm{l} \% 20 \mathrm{Justicia} \% 20$ Espanol $\% 20020507$.pdf

86 Mecanismo de Seguimiento de la Convención de Belém do Pará, MESECVI, Segunda Conferencia de Estados Parte, 9-10 de julio de 2008, Caracas, Venezuela. Colombia, Informe de país, OEA/Ser.L/II.7.10, 23 de junio de 2008. Disponible en: http://www.oas.org/es/MESECVI/ informesnacionales.asp

87 Nadia Constanza López-Téllez, Violencias contra las mujeres: presencias institucionales, movilizaciones sociales y prácticas legislativas. El caso de la incidencia feminista para el logro de la Ley contra la Violencia hacia las Mujeres (Tesis de maestría en estudios políticos y relaciones internacionales, Universidad Nacional de Colombia, Bogotá, 2009). Disponible en: http://www.bdigital.unal.edu.co/2433/1/nadialopeztellez.2009.pdf. Claudia CeCILIA RamíREZCARDONA, Crónica del proceso de formulación y aprobación de la Ley sobre Violencia contra la Mujer (Corporación Sisma Mujer, Bogotá, 2008). Disponible en: http://www.bdigital.unal. edu.co/48773/1/cronicadelprocesodeformulacion.pdf

En Estados Unidos, el movimiento de mujeres maltratadas ha promovido políticas para lograr una persecución penal más activa (por ejemplo, la persecución penal obligatoria). Los activistas insisten en que la violencia doméstica es un delito público o una violación de los derechos humanos, por lo que el Estado tiene la obligación de procesar y castigar estos delitos de manera agresiva.

Hay aproximaciones en conflicto frente a la persecución penal obligatoria de los casos de violencia doméstica. De un lado, algunos académicos y expertos argumentan que esta política es la respuesta apropiada a la violencia doméstica: Donna WiLls, Domestic Violence: The Case 
proactiva "quitan la decisión de si procesar o no al agresor de los hombros de la víctima y la ponen donde debe estar: en la discreción de los fiscales cuyo trabajo es hacer cumplir las leyes penales de la sociedad y atribuir la responsabilidad a los delincuentes por sus delitos"88. Así, el agresor tiene menos incentivos para controlar o intimidar a la víctima, porque no es ella quien controla el inicio de la persecución.

Sin embargo, estas estrategias enfocadas en la criminalización y persecución de la VIF implican dilemas filosóficos y políticos para los grupos feministas. En primer lugar, en el sistema de justicia penal, el objetivo de control de criminalidad puede superar los mensajes feministas sobre las construcciones de género y la desigualdad de género ${ }^{89}$. En segundo lugar, un procesamiento más activo y medidas de control de criminalidad más fuertes pueden desincentivar que las mujeres busquen ayuda en las instituciones estatales. En tercer lugar, la promoción de la imagen de las mujeres víctimas de VIF, como una típica víctima, puede reforzar los estereotipos sobre las mujeres (por ejemplo, debilidad, vulnerabilidad

for Aggressive Prosecution, 7 UCLA Women's Law Journal, 173-182, 173 (1996). Disponible en: http://escholarship.org/uc/item/7jq4p3kf. Michelle Madden Dempsey, Prosecuting Domestic Violence: A Philosophical Analysis, 222 (Oxford University Press, Oxford, New York, 2009). Reva B. Siegel sostiene que la persecución penal obligatoria envía el mensaje de que el Estado no tolerará este tipo de violencia. Reva B. SiEgEL, "The Rule of Love": Wife Beating as Prerogative and Privacy, 105 Yale Law Journal, 8, 2117-2207 (1996). Disponible en: http:// digitalcommons.law.yale.edu/cgi/viewcontent.cgi?article $=2092 \&$ context $=$ fss_papers. Con el fin de que las estrategias de persecución penal obligatoria sean eficaces, algunos expertos recomiendan la participación obligatoria de las víctimas, a pesar de que esta medida afecte la autonomía de las mujeres. De acuerdo con CHERYl HANnA, "Los beneficios sociales obtenidos a través de esta respuesta de la justicia penal a la violencia doméstica son muy superiores a los costos a corto plazo frente a la autonomía de las mujeres y la seguridad colectiva". CHERYL Hanna, No Right to Choose: Mandated Victim Participation in Domestic Violence Prosecutions, 109 Harvard Law Review, 8, 1849-1910 (1996). Disponible en: https://www.researchgate.net/publication/228136350_No_Right_to_Choose_Mandated_Victim_Participation_in_Domestic_ Violence_Prosecutions

De otro lado, los críticos de la persecución penal obligatoria resaltan que esta política transfiere el poder de los miembros masculinos de la familia al Estado y los fiscales. Como resultado de ello, el régimen de persecución penal obligatoria reduce la agencia de las víctimas y refuerza su dependencia. Linda G. Mills, Killing Her Softly: Intimate Abuse and the Violence of State Intervention, 113 Harvard Law Review, 2, 550-613 (1999). Disponible en: http://cyber.law.harvard.edu/vaw00/mills.html. Jeannie Suk, Criminal Law Comes Home, 116 Yale Law Journal, 2-70 (2006). Disponible en: http://papers.ssrn.com/sol3/papers.cfm?abstract_id=939619

88 Donna Wills, Domestic Violence: The Case for Aggressive Prosecution, 7 UCLA Women's Law Journal, 173-182 (1996). Disponible en: http://escholarship.org/uc/item/7jq4p3kf

89 Aya Gruber, Rape, Feminism, and the War on Crime, 84 Washington Law Review, 581-658 (2009). Disponible en: https://digital.law.washington.edu/dspace-law/bitstream/handle/1773.1/175/ Gruber_Author\%20Copy.pdf?sequence=1 
e indefensión $)^{90}$. En cuarto lugar, algunas leyes penales en contra de la violencia y a favor de las políticas de enjuiciamiento más activo pueden ser incompatibles con la teoría feminista sobre la agencia y la autonomía de la mujer ${ }^{91}$. Algunos defensores de las mujeres y académicos afirman que las estrategias de control de criminalidad transfieren el poder de los miembros masculinos de la familia al Estado y a los fiscales, en tanto las mujeres son consideradas vulnerables, débiles e incapaces para presentar una queja o para salir del ciclo de violencia. Como resultado, la intervención pública activa y la persecución penal reducen la agencia de las víctimas y refuerzan su dependencia ${ }^{92}$. De hecho, estas estrategias a favor de la acusación y del control de criminalidad aumentan la subordinación de la autonomía individual en el espacio doméstico frente al control del Estado, en nombre del interés público ${ }^{93}$. Muchos académicos han argumentado que la justicia penal y el derecho penal tienen una capacidad muy limitada para transformar las jerarquías de género y erradicar las desigualdades estructurales ${ }^{94}$.

Algunos expertos señalan que las normas centradas en el enjuiciamiento y el castigo de la VIF pueden oprimir a grupos vulnerables, ya que la aplicación de estas reglas ha sido tradicionalmente selectiva con base en factores como la raza y la clase. Las estrategias

90 Aya Gruber, Rape, Feminism, and the War on Crime, 84 Washington Law Review, 581-658, 622-625 (2009). Disponible en: https://digital.law.washington.edu/dspace-law/bitstream/ handle/1773.1/175/Gruber_Author\%20Copy.pdf?sequence=1. RATNA KAPUR, The Tragedy of Victimization Rhetoric: Resurrecting the "Native" Subject in International/Post-Colonial Feminist Legal Politics, 15 Harvard Human Rights Journal, 1, 1-38, 18 (2002).

91 Por ejemplo, Frances OLSEN argumenta que una ley de California sobre violación para proteger a las mujeres menores de edad reforzaba estereotipos de la mujer, y afectaba su libertad sexual. Frances Olsen, Statutory Rape: A Feminist Critique of Rights Analysis, 63 Texas Law Review, 387-432 (1984). En el mismo sentido, JeAnnie SuK señala que el uso de las órdenes de protección para prohibir la convivencia y el contacto de la pareja en los casos de violencia doméstica genera un divorcio de facto impuesto por el Estado, lo cual elimina la autonomía de la víctima. Jeannie Suk, Criminal Law Comes Home, 116 Yale Law Journal, 2-70 (2006). Disponible en: http://papers.ssrn.com/sol3/papers.cfm?abstract_id=939619

92 Cheryl Hanna, No Right to Choose: Mandated Victim Participation in Domestic Violence Prosecutions, 109 Harvard Law Review, 8, 1849-1910, 1857 (1996). Disponible en: https://www. researchgate.net/publication/228136350_No_Right_to_Choose_Mandated_Victim_ Participation_in_Domestic_Violence_Prosecutions

93 Linda G. Mills, Killing Her Softly: Intimate Abuse and the Violence of State Intervention, 113 Harvard Law Review, 2, 550-613 (1999). Disponible en: http://cyber.law.harvard.edu/vaw00/ mills.html

94 Aya Gruber, Rape, Feminism, and the War on Crime, 84 Washington Law Review, 581-658 (2009). Disponible en: https://digital.law.washington.edu/dspace-law/bitstream/handle/1773.1/175/ Gruber_Author\%20Copy.pdf?sequence=1. SAlly Engle Merry, Gender Violence: A Cultural Perspective (Wiley-Blackwell, Hoboken, New Jersey, 2009). 
punitivas, por lo general, se dirigen a hombres que pertenecen a grupos vulnerables o tradicionalmente discriminados ${ }^{95}$. Los datos disponibles sobre características de las personas privadas de la libertad por VIF en Colombia parecen confirmar lo anterior. Entre 2009 y 2015, la mayoría de los internos por VIF tenía un estatus socioeconómico bajo, teniendo en cuenta su edad y nivel de estudios. Los datos solo incluyen infractores mayores de 18 años y el $76 \%$ de las personas que ingresaron al sistema penitenciario por VIF es mayor de 30 años. La mayoría de los internos por VIF contaba con niveles bajos de educación (gráfico 11). El 39\% tenía educación primaria, 53\% tenía educación secundaria, 1,9\% tenía educación técnica, $0,92 \%$ educación teconológica, $1,6 \%$ obtuvo un título profesional y $0,4 \%$ cursó estudios de posgrado ${ }^{96}$.

\section{Gráfico 11}

\section{Personas que ingresaron al sistema penitenciario por el delito de VIF, por nivel de escolaridad (2009-2015)}

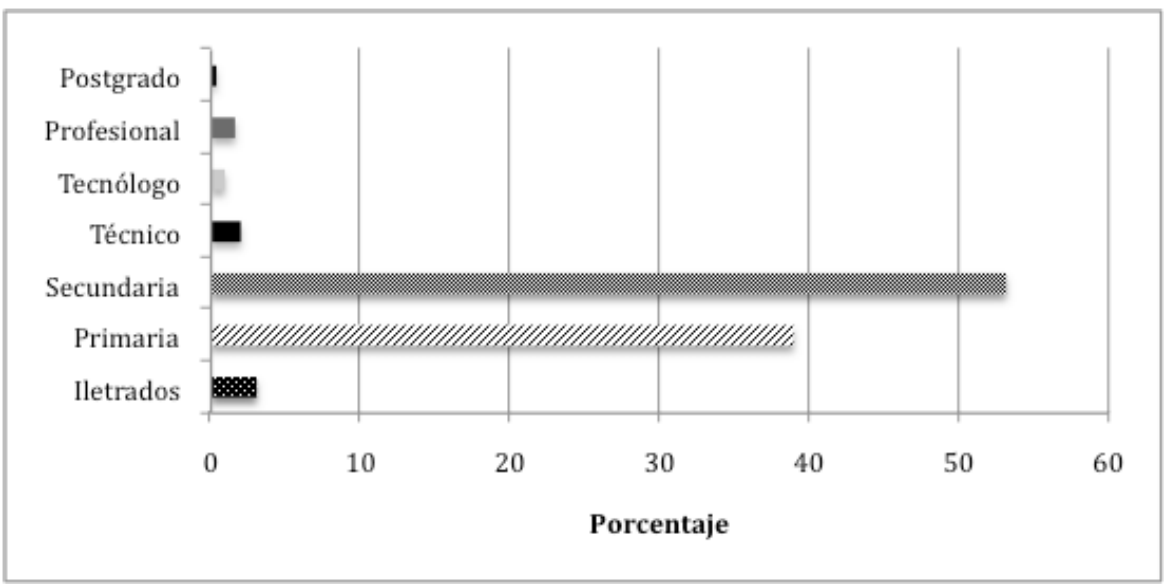

Fuente: Instituto Nacional Penitenciario Carcelario, INPEC

95 Kimberle Crenshaw, Mapping the Margins: Intersectionality, Identity Politics, and Violence against Women of Color, 43 Stanford Law Review, 6, 1241-1299 (1991). Disponible en: http:// socialdifference.columbia.edu/files/socialdiff/projects/Article__Mapping_the_Margins_by_ Kimblere_Crenshaw.pdf. AyA Gruber, Rape, Feminism, and the War on Crime, 84 Washington Law Review, 581-658, 654 (2009). Disponible en: https://digital.law.washington.edu/dspace-law/ bitstream/handle/1773.1/175/Gruber_Author\%20Copy.pdf?sequence=1. SALly ENGLE MERry, Gender Violence: A Cultural Perspective (Wiley-Blackwell, Hoboken, New Jersey, 2009).

96 Teniendo en cuenta que los datos sobre el número de internos solo incluye infractores mayores de 18 años y que el 76\% de los internos es mayor de 30 años, el nivel de instrucción puede ser una variable proxy de su nivel socioeconómico (SES). Supra nota 14. 
Eugenio Raúl ZafFARONi sostiene que el poder punitivo es selectivo y discriminatorio, mientras que el discurso feminista es antidiscriminatorio. ZAFFARONI argumenta que parece poco probable que una herramienta discriminatoria se pueda utilizar para luchar contra la discriminación; de hecho, las reformas feministas al derecho penal pueden reforzar y legitimar el poder punitivo y sus efectos discriminatorios ${ }^{97}$. JULIETA LEMAITRE-RIPOLL señala que esta cuestión hizo que ella se alejara de ciertas estrategias orientadas a la reforma de la legislación penal en Colombia ${ }^{98}$.

De otro lado, Isabel Cristina Jaramillo-Sierra ha cuestionado si la justicia penal es una verdadera solución para resolver los problemas relacionados con la VIF. Esta autora afirma que el resultado de un enfoque punitivo sería prisión para el agresor. En esas circunstancias, las consecuencias son: la mujer víctima se convertiría en jefe de la familia durante el encarcelamiento de su pareja; el agresor estaría en una "escuela del delito"; y los hijos sufrirían la ausencia del padre. La pregunta entonces sería ¿por qué una mujer desearía formular una denuncia? ISABEL CRISTINA JARAMILLO-SIERRA defiende que, por el contrario, otros mecanismos - como la acción de tutela - pueden tener un efecto beneficioso simbólico que puede ayudar a las mujeres a romper los ciclos de violencia ${ }^{99}$.

Otro mecanismo posible para tratar los casos de VIF es la justicia restaurativa. Aunque el uso de programas de justicia restaurativa para abordar la VCM es muy controversial, algunas feministas sugieren potenciales beneficios de un enfoque de justicia restaurativa. De acuerdo con MARTHA Minow, los programas de justicia restaurativa ofrecen arreglos institucionales para las víctimas que prefieren respuestas restaurativas a la violencia ${ }^{100}$. La autora men-

97 Eugenio Raúl ZafFaroni, El discurso feminista y el poder punitivo, en Las trampas del poder punitivo. El género del derecho penal, 19-30 (HAYdéE BIRGIN, comp., Editorial Biblos, Buenos Aires, 2000).

98 Julieta Lemaitre-Ripoll, El derecho como conjuro. Fetichismo legal, violencia y movimientos sociales (Universidad de los Andes, Siglo del Hombre Editores, Bogotá, 2009). Disponible en: https://www.academia.edu/3862405/LEMAITRE_RIPOLL_J__El_derecho_como_conjuro. _Uniandes_y_Siglo_del_Hombre_Editores._Bogot $\%$ C3\%A1._2009?auto=download

99 Isabel Cristina Jaramillo-Sierra, El "hogar”, ¿público o privado? A propósito de la jurisprudencia de la Corte Constitucional Colombiana en materia de violencia entre cónyuges, en Derecho constitucional: perspectivas críticas, vol. 1, 100-144 (MANuel José CePEda-EsPinosa, ed., Siglo del Hombre Editores, Bogotá, 1999).

100 Martha Minow, Between Vengeance and Forgiveness: Feminist Responses to Violent Injustice, 32 New England Law Review, 967-981, 981 (1998). Disponible en: http://www.nesl.edu/userfiles/ file/lawreview/vol32/4/minow.htm 
cionada sostiene que la justicia restaurativa puede atender los deseos de la víctima, tratar de romper los ciclos de violencia, y ayudar a las víctimas a ir más allá de la ira y más allá de un sentimiento de impotencia. MARTha Minow también afirma que la justicia restaurativa puede reconocer la humanidad del agresor y la víctima, facilitar la prevención del delito y la restauración, intentar reparar las relaciones sociales y la paz, y garantizar el reconocimiento público y la condena de los abusos ${ }^{101}$. Por otra parte, los proponentes de la justicia restaurativa insisten en que las víctimas pueden empoderarse mediante la participación en la resolución de sus conflictos dentro de un programa de justicia restaurativa. Además, estos expertos destacan que un mecanismo de justicia restaurativa puede ser más sensible a las necesidades e intereses de la víctima ${ }^{102}$.

En Colombia, es de reiterar que las prácticas de la conciliación en casos de VIF han afectado los intereses de las mujeres víctimas ${ }^{103}$. Tal vez uno de los problemas centrales ha sido que la aplicación de la conciliación no ha atendido los principios y valores fundamentales de la justicia restaurativa. Adicionalmente, la implementación de la conciliación en casos de VIF no ha abordado en detalle los problemas de la jerarquía de género.

De acuerdo con Julieta LEMAITRE-Ripoll, si la conciliación fuera transformada siguiendo una perspectiva feminista, podría ser un espacio para lograr la justicia para las mujeres ${ }^{104}$. En el mismo sentido, algunos académicos sugieren que la respuesta a la VCM

101 Martha Minow, Between Vengeance and Forgiveness: Feminist Responses to Violent Injustice, 32 New England Law Review, 967-981, 969-970 (1998). Disponible en: http://www.nesl.edu/ userfiles/file/lawreview/vol32/4/minow.htm

102 John Braithwaite, Building Legitimacy through Restorative Justice, en Legitimacy and Criminal Justice: International Perspectives, 146-162 (ToM R. TYLER, ed., Russell Sage Foundation, New York, 2007). John Braithwaite, Restorative Justice and a Better Future, 76 The Dalhousie Review, 1, 9-32 (1996). Disponible en: https://dalspace.library.dal.ca/handle/10222/63177, https://dalspace.library.dal.ca/bitstream/handle/10222/63177/dalrev_vol76_iss1_pp9_31. pdf?sequence $=1 \&$ isAllowed=y. Julio Andrés SAmpedro-Arrubla, Las víctimas y el sistema penal: aproximación al proceso penal desde la victimología (Pontificia Universidad Javeriana, Bogotá, 2010). Julio Andrés SAmpedro-Arrubla, La humanización del proceso penal. Una propuesta desde la victimología (Serie Lex Nova, Legis, Bogotá, 2003).

103 Julieta Lemaitre-Ripoll, Justicia injusta: una crítica feminista a la conciliación en violencia conyugal, 27 Revista de Derecho Privado, 73-98 (2002). Disponible en: https://derechoprivado. uniandes.edu.co/components/com_revista/archivos/derechoprivado/pri223.pdf

104 Julieta Lemaitre-Ripoll, Justicia injusta: una crítica feminista a la conciliación en violencia conyugal, 27 Revista de Derecho Privado, 73-98 (2002). Disponible en: https://derechoprivado. uniandes.edu.co/components/com_revista/archivos/derechoprivado/pri223.pdf 
requiere un enfoque que difiere de las prácticas comunes de justicia restaurativa e incluye un marco feminista ${ }^{105}$.

Un enfoque feminista a los mecanismos de justicia restaurativa enfatiza el patrón de la desigualdad de poder entre el agresor y la víctima. Por lo tanto, este enfoque se opone a la neutralidad del facilitador y propone un papel más directivo para el facilitador y una participación más activa de los defensores de las víctimas. Adicionalmente, una aproximación feminista a la justicia restaurativa reclama la importancia de tener en cuenta las decisiones de la víctima y sus necesidades en cuanto a la respuesta a la violencia. La víctima debe tener la opción de decidir si participar en programas de justicia restaurativa o no, sin presión. El enfoque feminista no está de acuerdo con la representación de las mujeres como impotentes, vulnerables, débiles e indefensas. Sin embargo, reconoce que la agencia de las mujeres puede estar restringida, en algunos casos, por las circunstancias, creencias y prácticas. Por lo tanto, se debe ofrecer a las mujeres víctimas la asistencia material, legal y psicológica adecuada para posibilitar decisiones relativamente autónomas. Por otra parte, un enfoque feminista de la justicia restaurativa exige garantías adicionales para proteger los derechos e intereses de las víctimas. Por ejemplo, se requieren mecanismos de seguimiento y sanciones para garantizar el cumplimiento de los acuerdos y los resultados restaurativos ${ }^{106}$.

105 Martha Minow, Between Vengeance and Forgiveness: Feminist Responses to Violent Injustice, 32 New England Law Review, 967-981, 981 (1998). Disponible en: http://www.nesl.edu/userfiles/file/ lawreview/vol32/4/minow.htm. Julie STubBs, Beyond Apology? Domestic Violence and Critical Questions for Restorative Justice, 7 Criminology and Criminal Justice, 2, 169-187 (2007). JULIE StubBs, Domestic Violence and Women's Safety: Feminist Challenges to Restorative Justice, en Restorative Justice and Family Violence, 42-61 (Heather Strang \& John Braithwaite, eds., 2002).

106 Martha Minow, Between Vengeance and Forgiveness: Feminist Responses to Violent Injustice, 32 New England Law Review, 967-981, 981 (1998). Disponible en: http://www.nesl.edu/userfiles/file/ lawreview/vol32/4/minow.htm. Julie StubBs, Beyond Apology? Domestic Violence and Critical Questions for Restorative Justice, 7 Criminology and Criminal Justice, 2, 169-187 (2007). JULIE StubBs, Domestic Violence and Women's Safety: Feminist Challenges to Restorative Justice, en Restorative Justice and Family Violence, 42-61 (Heather Strang \& John Braithwaite, eds., 2002). 


\section{CONCLUSIONES}

En el contexto del CPP de 2004, los actores que promueven agendas de justicia restaurativa y agendas punitivas han competido para definir las medidas para tratar los casos de VIF. En las reglas del CPP de 2004, prevaleció el enfoque de justicia restaurativa. En la práctica, la conciliación se mantuvo como la respuesta predominante del Estado frente a la VIF, y los agresores rara vez fueron enviados a prisión. Sin embargo, los datos disponibles sugieren que las audiencias de conciliación no cumplían los principios fundamentales, valores y exigencias de la justicia restaurativa. Adicionalmente, las académicas feministas y el movimiento de mujeres han planteado una serie de preocupaciones con respecto a la implementación de la conciliación en casos de VIF. Una de las preocupaciones centrales es que los fiscales no toman esta forma de violencia en serio y favorecen la conciliación porque creen que el maltrato es un delito menor, privado.

Teniendo en cuenta la regulación de la VIF como un delito menor en el CPP de 2004 y las prácticas problemáticas de las autoridades, los actores que promueven una mayor protección para las mujeres víctimas de la VIF promovieron con éxito una reacción punitiva contra el CPP de 2004. Los datos disponibles sugieren que las reformas legales punitivas diseñadas para combatir la violencia dentro de la familia han tenido resultados mixtos. Aunque la tasa de prisión por VIF aumentó significativamente, la población reclusa por VIF es relativamente pequeña en comparación con el número de internos por otros delitos como el porte de armas. Además, las reformas legales punitivas pueden haber tenido el resultado no deseado de alejar a algunas de las víctimas del proceso penal. Así las cosas, la capacidad de las medidas de control de criminalidad para proteger a las mujeres que sufren VIF ha resultado limitada.

Mi argumento es que los defensores de las mujeres deben ser cuidadosos frente a las estrategias punitivas y de control de la criminalidad para combatir la VIF, ya que estas tienen un efecto complejo. Por un lado, el enjuiciamiento y el castigo penal de la VCM en el hogar hacen visibles las situaciones de injusticia y pueden contribuir a empoderar a las mujeres, al representar esta forma de violencia como violaciones a los derechos humanos $\mathrm{y}$ 
delitos graves. Por otro lado, un enfoque punitivo puede tener un efecto desempoderador. Las estrategias punitivas pueden generar riesgos o límites para la emancipación de las mujeres víctimas, ya que estas estrategias restringen la autonomía y la agencia de las mujeres para resolver sus conflictos. Además, las estrategias de control de criminalidad implican un sistema de disciplina y control que penaliza principalmente a los hombres de grupos vulnerables y tradicionalmente discriminados.

Esta investigación sugiere que las respuestas del Estado que se centran solo en medidas punitivas o solo en la conciliación son problemáticas. Sería importante tener en cuenta respuestas híbridas a la VCM que combinen la justicia penal tradicional y programas de justicia restaurativa. Tales programas restaurativos deben incluir un enfoque feminista y cumplir los valores y principios de la justicia restaurativa. El diseño de las respuestas a la VIF debe tener en cuenta que esta forma de violencia implica particularidades relacionadas a la relación única entre la víctima y el agresor. Respuestas híbridas a la VIF presentan alternativas que pueden respetar la agencia de las mujeres víctimas, ofrecer opciones para las víctimas que prefieren resultados restaurativos, y atender las necesidades y contextos particulares de las víctimas. Teniendo en cuenta que la justicia restaurativa y el castigo son respuestas complementarias, en un caso particular, la pregunta sería cuál de estas respuestas es más adecuada. A veces, la justicia restaurativa podría ser satisfactoria; otras veces, el castigo también podría ser necesario. 


\section{BIBLIOGRAFÍA}

\section{Libros}

American Psychological Association, APA, Report of the APA Task Force on Socioeconomic Status (American Psychological Association, APA, Task Force on Socioeconomic Status, Washington, 2007). Disponible en: https://www.apa. $\mathrm{org} / \mathrm{pi} / \mathrm{ses} /$ resources/publications/task-force-2006.pdf

Báez, Carolina; Barraza, Cecilia; Buenahora, Nathalia; Caicedo, Luz Piedad \& LóPez, CARolina, La situación de las mujeres víctimas de violencias de género en el sistema penal acusatorio (Serie Acceso a la Justicia, 1, Corporación Humanas, Centro Regional de Derechos Humanos y Justicia de Género, Bogotá, 2008). Disponible en: http://www.bdigital.unal.edu.co/45466/

Beristain, Antonio, Victimología: nueve palabras clave (Tirant Lo Blanch, Valencia, 2000).

Colombia, Comisión Asesora de Política Criminal, Informe final. Diagnóstico y propuesta de lineamientos de política criminal para el Estado colombiano (Ministerio de Justicia y del Derecho, Agencia Presidencial de Cooperación Internacional de Colombia, APC Colombia, Unión Europea, Bogotá, 2012). Disponible en: https://www.minjusticia.gov.co/Portals/0/INFO $\% 20$ POLI\%20CRIMINAL_ FINAL23NOV.pdf

Dempsey, Michelle Madden, Prosecuting Domestic Violence: A Philosophical Analysis (Oxford University Press, Oxford, New York, 2009).

Dubber, Markus Dirk, Victims in the War on Crime: The Use and Abuse of Victims' Rights (New York University Press, New York, 2006).

Fineman, Martha \& Mykitiuk, Roxanne, eds., The Public Nature of Private Violence: The Discovery of Domestic Abuse (Routledge, New York, 1994).

Fondo de Desarrollo de las Naciones Unidas para la Mujer, UNIFEM, Fondo de Población de las Naciones Unidas, UNFPA, Organización Internacional para las Migraciones, OIM, Programa Integral contra Violencias de Género, Estudio sobre tolerancia social e institucional a la violencia basada en género en Colombia (Fondo de las Naciones Unidas y el Gobierno de España para el cumplimiento de los Objetivos de Desarrollo del Milenio, MDGF, Madrid, Bogotá, 2010). Disponible en: http://www.mdgfund.org/sites/default/files/ GEN_ESTUDIO_Colombia_Tolerancia $\% 20$ social $\% 20 \mathrm{e} \% 20$ institucional $\% 20$ $\mathrm{a} \% 201 \mathrm{a} \% 20$ violencia $\% 20 \mathrm{de} \% 20$ genero.pdf

Lemaitre-Ripoll, Julieta, El derecho como conjuro. Fetichismo legal, violencia y movimientos sociales (Universidad de los Andes, Siglo del Hombre Editores, Bogotá, 2009). Disponible en: https://www.academia.edu/3862405/LEMAITRE_ RIPOLL_J._El_derecho_como_conjuro._Uniandes_y_Siglo_del_Hombre_ Editores._Bogot $\%$ C3\%A1._2009?auto=download

Lewis, Susan H., Unspoken Crimes: Sexual Assault in Rural America (National Sexual Violence Resource Center, NSVRC, Enola, Pennsylvania, 2003). Disponible en: http://www.nsvrc.org/sites/default/files/Publications_NSVRC_Booklets_ Unspoken-Crimes-Sexual-Assault-in-Rural-America\%20.pdf 
Merry, Sally Engle, Gender Violence: A Cultural Perspective (Wiley-Blackwell, Hoboken, New Jersey, 2009).

Organization of American States, OAS, Inter-American Commission on Human Rights, IACHR (Organización de los Estados Americanos, OEA, Comisión Interamericana de Derechos Humanos, CIDH), Access to Justice for Women Victims of Violence in the Americas, OEA/Ser.L/V/II, Doc. 68, 20 January 2007 (Organization of American States, OAS, Inter-American Commission on Human Rights, CIDH, Washington, 2007). Disponible en: https://www.cidh.oas.org/ women/Access $07 /$ Report $\% 20$ Access $\% 20$ to $\% 20$ Justice $\% 20$ Report $\% 20$ English $\% 20$ 020507.pdf, http://www.cidh.oas.org/pdf $\% 20$ files/Informe $\% 20$ Acceso $\% 20$ a $\% 20$ la\%20Justicia\%20Espanol\%20020507.pdf

Policía Nacional de Colombia, Lineamientos generales de política para la Policía Nacional de Colombia (Policía Nacional de Colombia, Bogotá, 2007). Disponible en: http://pdba.georgetown.edu/Security/citizensecurity/Colombia/politicas/ lineamientospolicia.pdf

Policía Nacional de Colombia, Lineamientos generales de política para la Policía Nacional de Colombia (Policía Nacional de Colombia, Bogotá, 2010). Disponible en: http://www.policia.gov.co/portal/page/portal/HOME/Lineamientos/TOMO $\% 20$ 0-LINEAMIENTOS $\% 20$ GENERALES $\% 20$ DE $\% 20$ POLITICA $\% 20$ PARA $\% 20$ LA\%20PONAL.pdf

Ptacek, James, Battered Women in the Courtroom: The Power of Judicial Responses (Northeastern Series on Gender, Crime and Law, Northeastern University Press, Lebanon, New Hampshire, 1999).

Quintero-Benavides, Alexandra, Derechos en Femenino ¿Hacia un real camino a la igualdad? VI Informe de Derechos Humanos de las Mujeres, 2010-2012 (Corporación Sisma Mujer, Red Nacional de Mujeres, Bogotá, 2013). Disponible en: http://www.justiciaypazcolombia.com/IMG/pdf/vi_informe_ddhh_de_las_ mujeres_-derechos_en_femenino.pdf

Ramírez-Cardona, Claudia Cecilia, Crónica del proceso de formulación y aprobación de la Ley sobre Violencia contra la Mujer (Corporación Sisma Mujer, Bogotá, 2008). Disponible en: http://www.bdigital.unal.edu.co/48773/1/ cronicadelprocesodeformulacion.pdf

Sampedro-Arrubla, Julio Andrés, La humanización del proceso penal. Una propuesta desde la victimología (Serie Lex Nova, Legis, Bogotá, 2003).

SAmpedro-Arrubla, Julio Andrés, Las víctimas y el sistema penal: aproximación al proceso penal desde la victimología (Pontificia Universidad Javeriana, Bogotá, 2010).

Sisma Mujer, Obstáculos para el acceso a la justicia de mujeres víctimas de violencia sexual en Colombia (2011).

United Nations Office on Drug and Crime, UNODC, The Handbook on Restorative Justice Programmes (Criminal Justice Handbook Series, United Nations Office on Drug and Crime, UNODC, Vienna, New York, 2006). Disponible en: https:// www.unodc.org/pdf/criminal_justice/06-56290_Ebook.pdf

Wills, María Emma, Inclusión sin representación: la irrupción política de las mujeres en Colombia 1970-2000 (Editorial Norma, Bogotá, 2007). 
World Health Organization, WHO, WHO Multi-Country Study on Women's Health and Domestic Violence against Women: Summary Report of Initial Results on Prevalence, Health Outcomes and Women's Responses (World Health Organization, WHO, Geneva, 2005). Disponible en: http://www.who.int/gender/ violence/who_multicountry_study/summary_report/summary_report_English2. pdf

\section{Colaboración en obras colectivas}

Braithwaite, John, Building Legitimacy through Restorative Justice, en Legitimacy and Criminal Justice: International Perspectives, 146-162 (TOM R. TYLER, ed., Russell Sage Foundation, New York, 2007).

Braithwaite, John, Principles of restorative justice, en Restorative Justice and Criminal Justice: Competing or Reconcilable Paradigms, 1-20 (Andreas von Hirsch, Julian V. Roberts, Anthony E. Bottoms, Kent Roach, Mara Schiff, eds., Hart Publishing, Oxford, 2003). Disponible en: https://www.anu.edu.au/fellows/ jbraithwaite/_documents/Articles/Principles $\% 20$ of $\% 20$ Restorative $\% 20 J u s t i c e$. pdf

Copelon, Rhonda, Intimate Terror: Understanding Domestic Violence as Torture, en Human Rights of Women: National and International Perspectives, 116152 (Rebecca J. Cook, ed., University of Pennsylvania Press, Philadelphia, Pennsylvania, 1994).

Jaramillo-Sierra, Isabel Cristina, El "hogar”, ¿público o privado? A propósito de la jurisprudencia de la Corte Constitucional Colombiana en materia de violencia entre cónyuges, en Derecho constitucional: perspectivas críticas, vol 1, 100-144 (Manuel José Cepeda-Espinosa, ed., Siglo del Hombre Editores, Bogotá, 1999).

MacKinnon, Catharine, On Torture: A Feminist Perspective on Human Rights, en Human Rights in the Twenty-First Century: A Global Challenge, 21-32 (KATHLEEN Mahoney \& Paul Mahoney, eds., Kluwer, Norwell, Massachusetts, 1993).

Marcus, Isabel, Reframing 'Domestic Violence': Terrorism in the Home, en The Public Nature of Private Violence: The Discovery of Domestic Abuse, 11-35 (MARTHA Fineman \& Roxanne Mykitiuk, eds., Routledge, New York, 1994).

Rico de Alonso, Ana; Hurtado, María Cristina \& Alonso, Juan Carlos, Naturaleza del conflicto en el área de atención de familia (Consejo Superior de la Judicatura, Pontificia Universidad Javeriana, Bogotá, 1999).

Stubbs, Julie, Domestic Violence and Women's Safety: Feminist Challenges to Restorative Justice, en Restorative Justice and Family Violence, 42-61 (Heather Strang \& John Braithwaite, eds., 2002).

Zaffaroni, Eugenio Raúl, El discurso feminista y el poder punitivo, en Las trampas del poder punitivo. El género del derecho penal, 19-30 (HAYdéE Birgin, comp., Editorial Biblos, Buenos Aires, 2000). 


\section{Revistas}

Aguirre, Katherine \& Restrepo, Jorge A., El control de armas como estrategia de reducción de la violencia en Colombia: pertinencia, estado y desafíos, 52 Revista Criminalidad, 1, 265-284 (2007). Disponible en: http://www.policia.gov.co/ imagenes_ponal/dijin/revista_criminalidad/vol52_1/07ElControl.pdf

Bello-Montes, Catalina, El control de las armas ligeras: retos y desafíos para el nuevo milenio, 47 Revista Criminalidad, Capítulo VI, Fortalecimiento y Logros de la Seguridad Democrática, 6-16 (2005). Disponible en: http://www.policia.gov.co/ imagenes_ponal/dijin/revista_criminalidad/vol47/14.pdf, http://www.policia.gov. co/portal/page/portal/HOME/publicaciones/revista_criminalidad/47

Beristain, Antonio, Hoy creamos una nueva ciencia cosmopolita e integradora: la victimología de máximos, después de Auschwitz, 54 Revista Vniversitas, 110, 461487 (2005). Disponible en: http://revistas.javeriana.edu.co/index.php/vnijuri/ article/view/14693/11849

Braithwaite, John, Restorative Justice and a Better Future, 76 The Dalhousie Review, 1, 9-32 (1996). Disponible en: https://dalspace.library.dal.ca/handle/10222/63177, https://dalspace.library.dal.ca/bitstream/handle/10222/63177/dalrev_vol76_iss1_ pp9_31.pdf?sequence $=1 \&$ isAllowed $=\mathrm{y}$

Braithwaite, John, Restorative Justice: Assessing Optimistic and Pessimistic Accounts, 25 Crime and Justice, 1-127 (1999). Disponible en: https://www.researchgate. net/publication/249188069_Restorative_Justice_Assessing_Optimistic_and_ Pessimistic_Accounts

Brown, Jennifer Gerarda, The Use of Mediation to Resolve Criminal Cases: A Procedural Critique, 43 Emory Law Journal, 1247-1309 (1994).

Christie, Nils, Conflicts as Property, 17 The British Journal of Criminology, 1, 1-15 (1977).

Crenshaw, Kimberle, Mapping the Margins: Intersectionality, Identity Politics, and Violence against Women of Color, 43 Stanford Law Review, 6, 1241-1299 (1991). Disponible en: http://socialdifference.columbia.edu/files/socialdiff/projects/ Article__Mapping_the_Margins_by_Kimblere_Crenshaw.pdf

Gruber, Aya, Rape, Feminism, and the War on Crime, 84 Washington Law Review, 581-658 (2009). Disponible en: https://digital.law.washington.edu/dspace-law/bitstream/ handle/1773.1/175/Gruber_Author\%20Copy.pdf?sequence $=1$

Hanna, Cheryl, No Right to Choose: Mandated Victim Participation in Domestic Violence Prosecutions, 109 Harvard Law Review, 8, 1849-1910 (1996). Disponible en: https://www.researchgate.net/publication/228136350_No_Right_to_Choose_ Mandated_Victim_Participation_in_Domestic_Violence_Prosecutions

KaPur, RATnA, The Tragedy of Victimization Rhetoric: Resurrecting the "Native" Subject in International/Post-Colonial Feminist Legal Politics, 15 Harvard Human Rights Journal, 1, 1-38 (2002).

Lemaitre-Ripoll, Julieta, Justicia injusta: una crítica feminista a la conciliación en violencia conyugal, 27 Revista de Derecho Privado, 73-98 (2002). Disponible en: https://derechoprivado.uniandes.edu.co/components/com_revista/archivos/ derechoprivado/pri223.pdf 
Mills, Linda G., Killing Her Softly: Intimate Abuse and the Violence of State Intervention, 113 Harvard Law Review, 2, 550-613 (1999). Disponible en: http://cyber.law. harvard.edu/vaw00/mills.html

Minow, Martha, Between Vengeance and Forgiveness: Feminist Responses to Violent Injustice, 32 New England Law Review, 967-981 (1998). Disponible en: http:// www.nesl.edu/userfiles/file/lawreview/vol32/4/minow.htm

Olden, Frances, Statutory Rape: A Feminist Critique of Rights Analysis, 63 Texas Law Review, 387-432 (1984).

Pineda-Duque, Javier \& Otero-Peña, Luisa, Género, violencia intrafamiliar e intervención pública en Colombia, 17 Revista de Estudios Sociales, 19-31 (2004). Disponible en: https://res.uniandes.edu.co/view.php/341/index.php?id=341

Procuraduría General de la Nación, Comisarías de Familia. Línea de Base Nacional, 6, 7 Procurando la Equidad, números especiales (2011, 2012). Primera parte disponible en: http://www.procuraduria.gov.co/portal/media/file/Procurando $\% 206 \% 20$ ene \%2012-12.pdf, segunda parte: http://www.procuraduria.gov.co/portal/media/ file/PROCURANDO7_WEB $\% 20$ final $\% 20$ nov\%2023.pdf

RoAch, Kent, Criminology, Four Models of the Criminal Process, 89 The Journal of Criminal Law and Criminology, 2, 671-716 (1999). Disponible en: http://scholarlycommons. law.northwestern.edu/cgi/viewcontent.cgi?article $=7000 \&$ context $=$ jclc

Siegel, Reva B., "The Rule of Love”: Wife Beating as Prerogative and Privacy, 105 Yale Law Journal, 8, 2117-2207 (1996). Disponible en: http://digitalcommons.law.yale. edu/cgi/viewcontent.cgi?article $=2092 \&$ context $=$ fss_papers

Singer, Jana B., The Privatization of Family Law, 5 Wisconsin Law Review, 1443-1567 (1992).

Stubbs, Julie, Beyond Apology? Domestic Violence and Critical Questions for Restorative Justice, 7 Criminology and Criminal Justice, 2, 169-187 (2007).

Suk, Jeannie, Criminal Law Comes Home, 116 Yale Law Journal, 2-70 (2006). Disponible en: http://papers.ssrn.com/sol3/papers.cfm?abstract_id=939619

Wills, Donna, Domestic Violence: The Case for Aggressive Prosecution, 7 UCLA Women's Law Journal, 173-182 (1996). Disponible en: http://escholarship.org/ uc/item/7jq4p3kf

\section{Tesis}

López-Téllez, Nadia Constanza, Violencias contra las mujeres: presencias institucionales, movilizaciones sociales y prácticas legislativas. El caso de la incidencia feminista para el logro de la Ley contra la Violencia hacia las Mujeres (Tesis de maestría en estudios políticos y relaciones internacionales, Universidad Nacional de Colombia, Bogotá, 2009). Disponible en: http://www.bdigital.unal.edu.co/2433/1/ nadialopeztellez.2009.pdf 


\section{Tratados internacionales}

Convención Interamericana para Prevenir, Sancionar y Erradicar la Violencia contra la Mujer, Convención de Belém do Pará, 9 de junio de 1994. Disponible en: http://www.oas.org/juridico/spanish/tratados/a-61.html, http://www.oas.org/ es/mesecvi/default.asp

\section{Normatividad colombiana}

Colombia, Acto legislativo 1 de 2012, Marco Jurídico para la Paz, por medio del cual se establecen instrumentos jurídicos de justicia transicional en el marco del artículo 22 de la Constitución Política y se dictan otras disposiciones, 48.508 Diario Oficial, 31 de julio de 2012. Disponible en: http://www.secretariasenado. gov.co/senado/basedoc/acto_legislativo_01_2012.html

Colombia, Constitución Política, 116 Gaceta Constitucional, 20 de julio de 1991. Segunda edición corregida disponible en: http://www.secretariasenado.gov.co/senado/ basedoc/constitucion_politica_1991.html

Colombia, Decreto 1861 de 1989, por el cual se introducen modificaciones al Código de Procedimiento Penal y se dictan otras disposiciones, 38.945 Diario Oficial, 18 de agosto de 1989. Disponible en: ftp://ftp.camara.gov.co/camara/basedoc/ decreto/1989/decreto_1861_1989.html

Colombia, Ley 294 de 1996, por la cual se desarrolla el artículo 42 de la Constitución Política y se dictan normas para prevenir, remediar y sancionar la violencia intrafamiliar, 42.836 Diario Oficial, 22 de julio de 1996. Disponible en: http:// www.secretariasenado.gov.co/senado/basedoc/ley_0294_1996.html

Colombia, Ley 575 de 2000, por medio de la cual se reforma parcialmente la Ley 294 de 1996, 43.889 Diario Oficial, 11 de febrero de 2000. Disponible en: http://www. secretariasenado.gov.co/senado/basedoc/ley_0575_2000.html

Colombia, Ley 890 de 2004, por la cual se modifica y adiciona el Código Penal, 45.602 Diario Oficial, 7 de julio de 2004. Disponible en: http://www.secretariasenado. gov.co/senado/basedoc/ley_0890_2004.html

Colombia, Ley 906 de 2004, por la cual se expide el Código de Procedimiento Penal de 2004, 45.658 Diario Oficial, 1 de septiembre de 2004. Disponible en: http://www. secretariasenado.gov.co/senado/basedoc/ley_0906_2004.html

Colombia, Ley 1142 de 2007, por medio de la cual se reforman parcialmente las Leyes 906 de 2004, 599 de 2000 y 600 de 2000 y se adoptan medidas para la prevención y represión de la actividad delictiva de especial impacto para la convivencia y seguridad ciudadana, 46.673 Diario Oficial, 28 de julio de 2007. Disponible en: http://www.secretariasenado.gov.co/senado/basedoc/ley_1142_2007.html

Colombia, Ley 1257 de 2008, por la cual se dictan normas de sensibilización, prevención y sanción de formas de violencia y discriminación contra las mujeres, se reforman los Códigos Penal, de Procedimiento Penal, la Ley 294 de 1996 y se dictan otras disposiciones, 47.193 Diario Oficial, 4 de diciembre de 2008. Disponible en: http:// www.secretariasenado.gov.co/senado/basedoc/ley_1257_2008.html 
Colombia, Ley 1453 de 2011, por medio de la cual se reforma el Código Penal, el Código de Procedimiento Penal, el Código de Infancia y Adolescencia, las reglas sobre extinción de dominio y se dictan otras disposiciones en materia de seguridad, 48.110 Diario Oficial, 24 de junio de 2011 Disponible en: http://www. secretariasenado.gov.co/senado/basedoc/ley_1453_2011.html

Colombia, Ley 1542 de 2012, por la cual se reforma el artículo 74 de la Ley 906 de 2004, Código de Procedimiento Penal, 48.482 Diario Oficial, 5 de julio de 2012. Disponible en: http://www.secretariasenado.gov.co/senado/basedoc/ ley_1542_2012.html

\section{Proyectos de Ley colombianos}

Acta de la Plenaria 60, del Senado 60, 22 de mayo de 2007, 331 Gaceta del Congreso, 19 de julio de 2007. Disponible en: http://www.imprenta.gov.co/gacetap/gaceta. mostrar_documento?p_tipo $=02 \&$ p_numero $=60 \&$ p_consec $=15947$

Acta de Plenaria 28, Senado, 1 de diciembre de 2010, 70 Gaceta del Congreso, 7 de marzo de 2011. Disponible en: http://servoaspr.imprenta.gov.co/gacetap/gaceta.nivel_3

Acta de Plenaria 66, Cámara, 30 de mayo de 2011, 669 Gaceta del Congreso, 8 de sepriembre de 2011. Disponible en: http://servoaspr.imprenta.gov.co/gacetap/ gaceta.nivel_3

Ponencia para primer debate al Proyecto de Ley 164 de 2010, Senado, por medio de la cual se reforman el Código Penal, el Código de Procedimiento Penal, el Código de Infancia y Adolescencia, las reglas sobre Extinción de Dominio y se dictan otras disposiciones en materia de seguridad, 850 Gaceta del Congreso, 3 de noviembre de 2010. Disponible en: http://www.imprenta.gov.co/gacetap/gaceta. mostrar_documento?p_tipo $=12 \&$ p_numero $=164 \&$ p_consec $=27508$

Ponencia para segundo debate al Proyecto de Ley 227 de 2012, Cámara; proyecto de ley 164 de 2011, Senado, por la cual se reforma el artículo 74 de la Ley 906 de 2004, Código de Procedimiento Penal, 305 Gaceta del Congreso, 4 de junio de 2012. Disponible en: http://servoaspr.imprenta.gov.co/gacetap/gaceta.nivel_3

Proyecto de Ley 23 de 2006, Cámara, por medio de la cual se reforman parcialmente las Leyes 906 de 2004 y 599 de 2000 y se adoptan medidas para la prevención y represión de la actividad delictiva de especial impacto para la convivencia y la seguridad ciudadana, Exposición de Motivos, 250 Gaceta del Congreso, 26 de julio de 2006. Disponible en: http://www.imprenta.gov.co/gacetap/gaceta. indice? v_num $=250 \&$ v_anog $=2006$

Proyecto de Ley 171 de 2006, Senado, por la cual se dictan normas para prevenir, erradicar y sancionar toda forma de violencia contra las mujeres, se reforman los Códigos Penal, de Procedimiento Penal, la Ley 294 de 1996 y se dictan otras disposiciones; acumulado con el Proyecto de Ley 98 de 2006, por la cual se reforma parcialmente la Ley 294 de 1996 y se dictan normas para la promoción integral de los derechos y de la igualdad de la mujer, 630 Gaceta del Congreso, 7 de diciembre de 2006. Disponible en: http://www.imprenta.gov.co/gacetap/ gaceta.mostrar_documento?p_tipo $=11 \&$ p_numero $=171 \&$ p_consec $=14170$

Proyecto de Ley 164 de 2011, Senado, por la cual se reforma parcialmente la Ley 906 de 
2004, Código de Procedimiento Penal, 853 Gaceta del Congreso, 11 de noviembre de 2011. Disponible en: http://servoaspr.imprenta.gov.co/gacetap/gaceta.nivel_3

Texto aprobado en plenaria, Proyecto de Ley 164 de 2010, Senado, por medio de la cual se reforma el Código Penal, el Código de Procedimiento Penal, el Código de Infancia y Adolescencia, las reglas sobre extinción de dominio y se dictan otras disposiciones en materia de seguridad, 1117 Gaceta del Congreso, 22 de diciembre de 2010. Disponible en: http://servoaspr.imprenta.gov.co/gacetap/gaceta.nivel_3

\section{Jurisprudencia colombiana}

Corte Constitucional, Sentencia C-1198-08, 4 de diciembre de 2008, magistrado ponente Nilson Pinilla-Pinilla. Disponible en: http://www.corteconstitucional.gov.co/ RELATORIA/2008/C-1198-08.htm

\section{Documentos, informes, reportes, direcciones web}

Corporación Excelencia en la Justicia, Balance de los primeros cinco años de funcionamiento del Sistema Penal Acusatorio en Colombia (2011). Disponible en: http://www.cej.org.co/index.php/publicaciones/libros/2599-balance-de-losprimeros-cinco-anos-de-funcionamiento-del-sistema-penal-acusatorio-encolombia

Corporación Excelencia en la Justicia, Balance diez años de funcionamiento del Sistema Penal Acusatorio en Colombia 2004-2014 (2015). Disponible en: http://www.cej. org.co/

Instituto Nacional de Medicina Legal y Ciencias Forenses, INML, Forensis. Disponible en: http://www.medicinalegal.gov.co/en/forensis1;jsessionid=D97E6C23C6AF2 7539AFAE237F1220E3D

Mecanismo de Seguimiento de la Convención de Belém do Pará, MESECVI, Segunda Conferencia de Estados Parte, 9-10 de julio de 2008, Caracas, Venezuela. Colombia, Informe de país, OEA/Ser.L/II.7.10, 23 de junio de 2008. Disponible en: http://www.oas.org/es/MESECVI/informesnacionales.asp

Policía Nacional de Colombia, Revista Criminalidad. Disponible en: http://www.policia. gov.co/portal/page/portal/HOME/publicaciones/revista_criminalidad/pub

Profamilia (2000, 2005, 2010). Encuesta Nacional de Demografía y Salud, ENDS. Disponible en: http://profamilia.org.co/investigaciones/ends/ 
